Review Article

\title{
Determining Factors in the Therapeutic Success of Checkpoint Immunotherapies against PD-L1 in Breast Cancer: A Focus on Epithelial-Mesenchymal Transition Activation
}

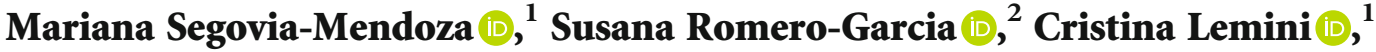 \\ and Heriberto Prado-Garcia ${ }^{2}{ }^{2}$ \\ ${ }^{1}$ Departamento de Farmacología, Facultad de Medicina, Universidad Nacional Autónoma de México, Coyoacán, \\ 04510 Ciudad de México, Mexico \\ ${ }^{2}$ Laboratorio de Onco-Inmunobiología, Departamento de Enfermedades Crónico-Degenerativas, Instituto Nacional de \\ Enfermedades Respiratorias, "Ismael Cosio Villegas" Calzada de Tlalpan 4502, Col. Sección XVI, Ciudad de México 14080, Mexico
}

Correspondence should be addressed to Heriberto Prado-Garcia; hpradog@yahoo.com

Received 15 October 2020; Revised 17 December 2020; Accepted 24 December 2020; Published 7 January 2021

Academic Editor: francesca bianchi

Copyright (c) 2021 Mariana Segovia-Mendoza et al. This is an open access article distributed under the Creative Commons Attribution License, which permits unrestricted use, distribution, and reproduction in any medium, provided the original work is properly cited.

Breast cancer is the most common neoplasm diagnosed in women around the world. Checkpoint inhibitors, targeting the programmed death receptor-1 or ligand-1 (PD-1/PD-L1) axis, have dramatically changed the outcome of cancer treatment. These therapies have been recently considered as alternatives for treatment of breast cancers, in particular those with the triplenegative phenotype (TNBC). A further understanding of the regulatory mechanisms of PD-L1 expression is required to increase the benefit of PD-L1/PD-1 checkpoint immunotherapy in breast cancer patients. In this review, we will compile the most recent studies evaluating PD-1/PD-L1 checkpoint inhibitors in breast cancer. We review factors that determine the therapeutic success of PD-1/PD-L1 immunotherapies in this pathology. In particular, we focus on pathways that interconnect the epithelialmesenchymal transition (EMT) with regulation of PD-L1 expression. We also discuss the relationship between cellular metabolic pathways and PD-L1 expression that are involved in the promotion of resistance in TNBC.

\section{Introduction}

Breast cancer is the most frequent female-associated neoplasm that affects women worldwide [1]. It can be defined as a set of biological and molecular heterogeneous diseases originating in the breast. Based on different clinicopathological characteristics, there are several types of breast cancer. According to the differential expression of estrogen receptor (ER), progesterone receptor (PR), and epidermal growth factor receptor type 2 (HER2), breast cancer has been traditionally classified into three different phenotypes: luminal (ER+/PR+), HER2+, and triple-negative breast cancer (TNBC) [2]. Within the TNBC phenotype, there are 6 subclasses characterized by the expression of different molecules $[3,4]$. TNBC is known to be the most aggressive phenotype, with few therapeutic opportunities and with poor patient prognosis. The luminal and HER2+ phenotypes are treated with target therapies against ER and HER2 proteins [5-7].

Current evidence has established that the response to therapy and the prognosis of breast cancer patients may be conditioned by the intrinsic heterogeneity of breast tumors, especially in TNBC [8]. The profile of tumor-infiltrating lymphocytes (TILs) and how it is conformed within the tumor has received special attention because the profile of TILs is also considered a crucial factor that determines the therapeutic response of different chemotherapeutic agents even in nonimmune based therapies [9]. In fact, the proportion and type of immune cells infiltrating the tumor can vary according to the molecular phenotype of this pathology [10]. In addition, the generation of resistance to conventional therapies is a critical concern in the clinic, in which immunotherapy has been considered an alternative in recent years. 
For all of the above, the employment of selective immune therapies has been an important clinical tool against cancer. More specifically, the use of immune-checkpoint inhibitors targeting the programmed death receptor-1/ligand-1 (PD$1 / \mathrm{PD}-\mathrm{L} 1$ ) axis has dramatically changed the outcome for cancer patients $[11,12]$.

\section{PD-1/PD-L1 Axis}

Tumors are known to use several mechanisms to disrupt the function of tumor-specific $\mathrm{T}$ cells, macrophages, and other immune cells. Among these mechanisms are the expression of ligands which bind to inhibitory receptors expressed on $\mathrm{T}$ cells, suppressing their function. T cells are activated by the interaction of the TCR/CD3 complex with a specific antigen presented by the APC, and costimulatory signals mediated by molecules such as CD28. TCR engagement and CD28 costimulation promote phosphorylation of a wide array of molecules involved in transduction pathways that promote $\mathrm{T}$ cell activation [13]. Conversely, several coinhibitory molecules have also been discovered that regulate the immune system, as is the case for $\mathrm{T}$ cells. In particular, the checkpoint PD1/PD-L1 axis is one of the best-known mechanisms that modulates the functioning of immune cells [14].

$\mathrm{PD}-1$ is a transmembrane protein that belongs to the $\mathrm{B} 7$ family of immune costimulatory/inhibitory molecules, and it is commonly expressed on the surface of activated $\mathrm{T}$ and B lymphocytes, myeloid cells, and TILs $[15,16]$. PD-1 has two known ligands, PD-L1 and PD-L2 [17, 18]. Different signaling pathways including NF- $\kappa \mathrm{B}, \mathrm{MAPK}, \mathrm{PI} 3 \mathrm{~K}, \mathrm{mTOR}$, and JAK/STAT have been shown to modulate the activatio$\mathrm{n}$ /expression of PD-1 as well as its ligands [19-21]. PD-1 induces its signaling pathway after $\mathrm{T}$ cell receptor- (TCR-) crosslinking. Upon TCR stimulation, the tyrosine residues of the immunoreceptor tyrosine-based switch motif (ITSM) on the cytoplasmic tail of PD-1 become phosphorylated, recruiting SHP-1 and SHP-2 phosphatases, which in turn dephosphorylate proximal signaling molecules downstream of the TCR, leading to a negative immunomodulation. The inhibition of the expression of transcription factors associated with effector cell function, including GATA3 (GATA Binding Protein 3), T-bet, and eomesodermin (Eomes) is promoted after TCR engagement and PD-1 interaction [22].

PD-L1 and PD-L2 show a different pattern of expression; while PD-L2 expression is limited to antigen-presenting cells (APCs), PD-L1 is expressed in wider arrays of tissues including APCs. Among the nonhematopoietic tissues that constitutively express PD-L1 are cells from immune privilege sites such as testes, cornea, placenta, and pancreatic islets. PD-L1 has been shown to act as a preponderant tumor evasion mechanism; therefore, the mechanisms that modulate its expression have been the subject of intense research [23]. Different articles have pointed out that amplification or mutations of important protooncogenes including Kirsten rat sarcoma viral oncogene homolog (KRAS), TP53, and hepatocyte growth factor receptor (HGFR or c-MET) are significantly associated with high levels of mRNA and protein expression of PD-L1 in lung cancer [24-26]. For instance, KRAS has been associated with the stabilization of AU-rich elements in the $3^{\prime}$ UTR region of PD-L1, as well as the reduction of the expression of genes related with the presentation of different antigens via MHC class I molecules to T cells [27]. Thus, antigen processing/presentation on immune cells is deregulated, which if joined to PD-L1 expression on cancer cells, results in a positive feedback that sustains the immune-resistant state [28].

$\mathrm{PD}-\mathrm{L} 1$ expression is also subject to epigenetic modifications. In this sense, the regulation of the expression of PDL1 has also been associated to the bromodomain extra terminal (BET) family in ovarian cancer [29]. The BET family consists of four different proteins (BRD2, BRD3, BRD4, and BRDT), which are implicated in the transcription modulation of some oncogenes through a bromodomain that recognizes promotor hystone lysine acetylation and recruits other transcription factors [30]. Recently, it was reported that BET proteins control the expression of PD-1 in activated $\mathrm{T}$ cells and PD-L1 in TNBC cells. In addition, these proteins also regulate IFN- $\gamma$ secretion by activated $\mathrm{T}$ cells when they are cocultivated with TNBC cells $[31,32]$. Different epigenetic changes including methylation and histone modification have been reported in the promoter of the PD-L1 gene in different types of cancer [33]. However, the role of these biological changes has been not deeply explored in breast cancer.

TNBC is also considered the most undifferentiated subtype within the variety of breast cancer. Interestingly, the number of gene copies of CD274 (the PD-L1 gene) has been found augmented in TNBC samples [34], which suggest that it is mostly feasible for TNBC tumors to develop immunoescape features. Several studies point out that the overexpression of PD-L1 is the result of a genomic amplification of chromosome 9p24.1, which encodes the PD-L1 gene [35]. The activation of Janus kinase 2 (JAK2)/STAT1 by the addition of IFN- $\gamma$ to TNBC cell cultures has been implicated in the amplification of chromosome 9p24.1 [36]. The actions described above draw attention due to the fact that IFN- $\gamma$ is a cytokine that usually participates in antitumor responses, although recent literature points out that IFN- $\gamma$ has dual effects in both tumor escape or tumor promotion [37].

Furthermore, the interaction of PD-L1 to its receptor in conjunction with other costimulatory molecules in naïve CD4+ T cells promote de novo transformation to the regulatory $\mathrm{T}$ cell (Treg) phenotype, through the inhibition of the mammalian target of rapamycin- (mTOR-) Akt signaling cascade [38]. The actions described above favor cancer immune escape [39]. Of note, other costimulatory proteins including CD80, a protein expressed on APCs and activated T cells, interacts with PD-L1. This interaction impairs binding of PD-L1 to PD-1, subsequently abrogating PD-1-mediated T cell suppression, which may be decisive for inducing optimal antitumoral responses [40].

\section{A Landscape for the Use of PD-1/PD-L1 Checkpoint Inhibitors in Breast Cancer}

The blockade of the PD-1/PD-L1 axis as a means for treating cancer was discovered by James P. Allison and Tasuku Honjo, who won the Nobel Prize of Physiology of Medicine for this breakthrough in 2018 [41]. Nowadays, the blockade of these molecules has been shown to be one of the most 
successful immunotherapies focused on enhancing the activity of immune cells against tumor cells. The above is closely related to the loss of immunologic control that is considered as one of the hallmarks of cancer [42]. The employment of these types of therapies has been widely proved in melanoma and non-small-cell lung cancer (NSCLC). In fact, different blockers of PD-1/PD-L1 interaction have been approved by the Food and Drug Administration (FDA) [43, 44]. Current methods to achieve efficient inhibition of PD-1/PD-L1 proteins are based on anti-PD-1 or anti-PD-L1 antibodies, gene silencing, and small-molecule pathway inhibition [45, 46]. It has been revealed that the PD-L1 molecule has a broad distribution in cancer, being located at serum levels, on the cancer cell membrane, and at the cytoplasmic or nuclear level, which limits the therapeutic efficacy of antibodies against this target [45].

Recently, the blockade of PD-1/PD-L1 has been investigated in breast cancer. In fact, the pathophysiological role of the PD-1/PD-L1 pathway has also been demonstrated using in vitro breast cancer models. First, the expression of PD-L1 has been reported in breast cancer cell lines with different phenotypes. MCF-7 (ER+) and MBA-MB-231 (TN) cells exhibit high levels of this protein. The coincubation of both types of breast cancer cells with human T lymphocyte cells (Jurkat cell line) or peripheral blood mononuclear cells (PBMCs) results in the inhibition of $\mathrm{T}$ cell activation via reduction of the expression of nuclear factor of activated T cells (NFAT), as well as cytokine expression (IL-2 and IFN- $\gamma$ ) [47]. Of note, blocking PD-1/PD-L1 interaction with the inhibitor A0-L significantly restores the activation of $\mathrm{T}$ cells, in addition to the secretion of IFN- $\gamma$ and IL- 2 cytokines by PBMC cells [47].

Some clinic reports have mentioned that not all patients with breast cancer have a good outcome after treatment with PD-1/PD-L1 checkpoint immunotherapies [48]. Several reasons are associated with the poor effectiveness of immunotherapies in breast cancer patients, such as the type and activation grade of immune infiltrating cells, the tumor cytokine pattern within the microenvironment, tumor cell mutations, exposition to chemotherapeutic agents, and an imbalance of antior proapoptotic proteins, along with the molecular phenotype of breast cancer [49]. Of note, approaches using therapeutic blocking of PD-1/PD-L1 have obtained better clinical results in breast cancer patients with a TN phenotype as compared with the luminal and HER2 phenotypes. However, little is known about what factors are crucial for an optimal response to PD-1/PD-L1 therapies in breast cancer [50].

PD-L1 has been shown to be expressed on both the membrane and cytoplasm by breast tumor cells but not by adjacent normal tissues [51]. PD-L1 expression has been detected by different techniques in all breast cancer subtypes. Its expression has been associated with larger tumors and absence of hormone receptors. The histological origin of the tumor cells seems to be related to PD-L1 expression, as invasive lobular carcinomas have lower expression of this molecule compared with ductal carcinomas [52]. Breast cancer cells also express PD-L1, although at lower levels compared to the TN phenotype. Immunohistochemical analyses of breast cancer tissues considering positive cells for PDL1 revealed that HER2-positive breast cancers also express
PD-L1 protein, although they showed lower PD-L1 levels compared to the TN phenotype. Nevertheless, PD-L1 expression in both phenotypes of breast cancer cells correlated with poor patient survival in patients that previously received chemo-, radio-, or endocrine therapy. In general, higher PD-L1 expression has been observed in TNBCs as compared to non-TNBCs; its upregulation has also been associated with overall, metastasis-free survival, and pathological complete response after neoadjuvant chemotherapy [51, 53-55].

Another important correlation between the expression of PD-L1 in TNBC might be also associated with the grade of cell differentiation. Supporting this fact, expression of this protein has been found to be increased in metastatic lung cancer samples compared with primary lung cancer lesions [24]. A similar PD-L1 expression pattern was found in breast cancer. Primary neoplasm lesions or tumors in early stages do not express high levels of PD-L1 as compared with the most aggressive counterpart present in advanced stages, where cell dedifferentiation is extremely marked [56]. In addition, PD-L1 expression is greater in patients with TN phenotype, lymph node metastasis, advanced clinical staging (high TNM stage), high Ki-67 score, and histopathological grading [52, 57-61]. However, no statistically significant relationship between PD-L1 expression in tumors, or within the tumor microenvironment, and clinicopathological parameters such as age, tumor size, and tumor grade has been established [58].

In spite of several efforts to standardize the detection of PD-L1 as a biomarker, the search of the expression of PDL1 in TNBC biopsies is a complex process due to the intertumoral heterogeneity in the expression of this molecule [62]. Besides tumor cells, the components of the stroma (e.g. fibroblasts, myofibroblasts, leukocytes, endothelial cells, macrophages, adipocytes, or extracellular matrix) might also express PD-L1 and play a role in inducing $\mathrm{T}$ cell dysfunction.

In this regard, the expression of PD-L1, as detected by immunohistochemical evaluation, has been directly related with a high grade of maturation of stroma, which can be defined by the cumulus of several mature collagen fibers into multiple layers. The mature stroma in conjunction with PDL1 expression predicts breast cancer outcome. Moreover, the relationship between hormone receptor negative tumors and the higher frequency of positive stromal PD-L1 staining has been observed [63]. Thus, identification of tumor stromal type, governed by the maturation state of collagen fibers, might be incorporated into clinical routine for achieving an optimal therapeutic scheme in breast cancer patients [63].

Additionally, some clinical reports have also evaluated the expression of PD-L1 in different samples of breast cancer patients in conjunction with the TIL population [64]. Interestingly, TN breast tumors are considered as the phenotype with the highest immune infiltration as compared with the other phenotypes [65]. Of note, there is an immunomodulatory subtype within the TNBC, which probably has a greater response to immunotherapies. This could partly explain why PD-L1 inhibitors alone or in combination with other therapies have been predominantly studied in the TN phenotype [66-68]. Additionally, expression of PD-L1 by cells from the tumor microenvironment, as well as the number of TILs, 
have emerged as crucial determining factors for breast cancer therapy, impacting in patient survival $[9,64,69]$. PD-L1 promotes an altered function of $\mathrm{T}$ cells [70, 71]. Thus, we hypothesize that the majority of the immune cells inside the tumor might be rendered dysfunctional because breast cancer samples with a TN phenotype also display high levels of PD-L1.

\section{PD-L1 Inhibitors}

Here, we present different PD-1/PD-L1 inhibitors that have been tested in breast cancer (Table 1), as well as other tumors. We describe some of their molecular characteristics and immune-activation capacity in addition to presenting molecular markers associated with prognosis.

4.1. Atezolizumab. Atezolizumab is a humanized $\mathrm{Fc} \gamma \mathrm{R}$ binding-deficient anti-PD-L1 antibody that was approved by the FDA as a first-line treatment for cisplatin-resistant metastatic urothelial carcinoma and for metastatic NSCLC $[72,73]$. In addition, atezolizumab has also been approved by the FDA as second-line therapy for advanced bladder cancer [74]. Atezolizumab has shown clinical improvement in TNBC patients with metastatic disease, reflected as longer overall survival in monotherapy and combined with chemotherapy [75-77]. In fact, in March 2019, the FDA approved atezolizumab in combination with chemotherapy based on paclitaxel for the treatment of metastatic TNBC patients with positive PD-L1 protein expression [78]. Unlike other malignancies, in breast cancer, some molecular markers have been recently associated to the patient's response to atezolizumab. In this regard, serum levels of the lactate dehydrogenase (LDH), a metabolic enzyme that converts pyruvate to lactate, are associated with reduced clinical benefit in breast cancer patients treated with atezolizumab monotherapy [22, 76]. This fact is relevant because, although atezolizumab may be able to inhibit the PD-L1 protein and activate the immune response, metabolic reprogramming of tumor cells will be a predominant way for cancer survival, as it has been established before in different types of cancer [79].

4.2. Avelumab. Avelumab is a human monoclonal antibody that targets PD-L1. It is approved by the FDA for the treatment of metastatic Merkel cell carcinoma (skin cancer) and advanced urothelial carcinoma $[80,81]$. Avelumab can activate both adaptive and innate immune mechanisms to destroy cancer cells, unlike other immune therapies directed against the PD-1/PD-L1 axis [82]. Avelumab has been shown to block PD-1/PD-L1 interaction, as well as to activate natural killer (NK) cells through a mechanism known as tumor-directed antibody-dependent cell-mediated cytotoxicity (ADCC). Thus, ADCC is thought to be promoted by the crystallizable fragment $(\mathrm{Fc})$ region belonging to avelumab, which engages with the Fc $\gamma$ receptors expressed on the NK cells $[82,83]$.

Avelumab has been proven in metastatic breast cancer patients. In general, avelumab shows not only a modest antitumor response but also an acceptable safety profile in patients with this disease, especially in the TNBC population, as evidenced by the good tolerability of the evaluated doses and the few reported side effects. In addition, the expression of PD-L1 in TILs identified in breast cancer samples was associated with a better probability of clinical response to avelumab in metastatic breast cancer patients [84]. Different parameters including tumor mutational burden, TIL composition, high microsatellite instability, mismatch-repair deficiency, gut microbiome, and HLA diversity are being evaluated for predicting the therapeutic response to avelumab or other immunotherapies against the PD-1/PD-L1 axis. However, to this date, no clinical or tumor intrinsic-associated parameters have been found; hence, the search for clinical parameters associated with better results still continues $[85,86]$.

4.3. Durvalumab. Durvalumab is also an anti-PD-L1 antibody that has demonstrated clinical efficacy in bladder and lung cancers $[87,88]$. The effect of this therapy has not been sufficiently evaluated in patients with TNBC, but the better clinical response is associated with increased stromal TILs (sTILs) and intratumoral TILs (iTILs), in addition to increased pretherapeutic PD-L1 expression on tumor cells. In addition, the administration of durvalumab is associated with the migration of TILs from the stroma toward the tumor cell nests. This increase in the infiltration of immune cells into the tumor was not only evaluated by hematoxylin and eosin staining but was also complemented by a softwareassisted standardized approach [89]. Although the increase in the infiltration of immune cells into the tumor did not refer to a specific immune population, it was considered as an indicator of durvalumab response. Nonetheless, the effect of durvalumab is still under investigation, because it has not shown significant changes in pathological complete response when durvalumab is administrated alone or in combination with chemotherapy in early TNBC. Moreover, thyroid dysfunction is a major side effect derived from durvalumab administration [90].

Atezolizumab, durvalumab, and avelumab bind to PD-L1 from various directions and with different binding sites. While atezolizumab binds to the upper side close to the $\mathrm{N}$ terminus of PD-L1, durvalumab and avelumab bind rather perpendicularly to PD-L1. Although any of these antibodies efficiently inhibit PD-1/PD-L1 interaction, they exhibit poor tissue/tumor penetrance due to their large size, which detrimentally affects the therapy. Thus, the development of low-molecular weight proteins or small molecules modulating $\mathrm{PD}-1 / \mathrm{PD}-\mathrm{L} 1$ signaling, in addition to their combination with blocking antibodies, might be a promising option for the complete PD-1/PD-L1 blockade in solid tumors [91].

\section{PD-1 Inhibitors}

5.1. Pembrolizumab. Pembrolizumab is a humanized antiPD-1 antibody that has been extensively tested in patients with solid tumors. Nowadays, pembrolizumab is the firstline treatment option for metastatic melanoma and NSCLC. In fact, this drug has been combined with different enzyme inhibitors or chemotherapeutic agents in clinical trials [92, 93]. The use of this drug in cancer treatment has demonstrated promising patient responses with minimal side effects [94]. Pembrolizumab alone has been evaluated in clinical 
TABLE 1: Types of PD-1/PD-L1 inhibitors tested in clinical trials mostly evaluated in breast cancer patients with TN phenotype.

\begin{tabular}{|c|c|c|c|c|}
\hline Inhibitor & Population of study & Treatment scheme & $\begin{array}{l}\text { Outstanding results/response rates } \\
\text { to therapy }\end{array}$ & References \\
\hline \multicolumn{5}{|c|}{ PD-L1 inhibitors } \\
\hline Atezolizumab & $\begin{array}{c}\text { Metastatic TNBC (mTNBC) } \\
\text { patients }\end{array}$ & $\begin{array}{l}\text { One or more doses of atezolizumab } \\
\text { (840 mg) combined with } \\
\text { nanoparticle albumin-bound- } \\
\text { (nab-) paclitaxel }\end{array}$ & $\begin{array}{c}\text { Antitumoral responses were } \\
\text { denoted by the change in tumor } \\
\text { burden } \\
\text { The progression-free survival } \\
\text { (PFS) was } 8.6 \text { months with the } \\
\text { combination of atezolizumab plus } \\
\text { nab-paclitaxel vs. } 5.1 \text { months with } \\
\text { the paclitaxel alone } \\
\text { The objective response rate (ORR) } \\
\text { was } 53.8 \% \\
\text { Overall survival (OS) was } 24.2 \\
\text { months with the combined } \\
\text { treatment vs. } 12.4 \text { months with } \\
\text { paclitaxel alone } \\
\text { No serious side effects were } \\
\text { reported }\end{array}$ & {$[75]$} \\
\hline Atezolizumab & $\begin{array}{l}\text { Patients with advanced } \\
\text { mTNBC }\end{array}$ & $\begin{array}{l}\text { Intravenous atezolizumab } \\
(840 \mathrm{mg}) \text { combined with nab- } \\
\text { paclitaxel }\left(100 \mathrm{mg} / \mathrm{m}^{2}\right) \text { on days } 1 \text {, } \\
8 \text {, and } 15 \text { of every } 28 \text {-day cycle }\end{array}$ & $\begin{array}{l}\text { The combined treatment increased } \\
\text { PFS in patients with mTNBC } \\
\text { PFS was } 7.2 \text { months with } \\
\text { atezolizumab plus nab-paclitaxel as } \\
\text { compared with } 5.5 \text { months with } \\
\text { nab-paclitaxel alone } \\
\text { OS was } 21.3 \text { months with } \\
\text { atezolizumab plus nab-paclitaxel } \\
\text { and } 17.6 \text { months with placebo plus } \\
\text { nab-paclitaxel } \\
\text { No serious side effects were } \\
\text { reported }\end{array}$ & {$[77]$} \\
\hline Avelumab & $\begin{array}{l}\text { Patients with locally advanced } \\
\text { or metastatic breast cancer }\end{array}$ & $\begin{array}{c}\text { Intravenous avelumab }(20 \mathrm{mg} / \mathrm{kg}) \\
\text { every } 2 \text { weeks for } 10 \text { months } \\
\text { approximately }\end{array}$ & $\begin{array}{c}\text { The study compared patients with } \\
\text { breast cancer of diverse phenotypes } \\
\text { The ORR of patients with the TN } \\
\text { phenotype was } 5.2 \% \text { versus } 2.8 \% \\
\text { found in patients with HER2- } \\
\text { /ER/PR+ phenotype } \\
\text { Additionally, the rate of PFS was } \\
\text { higher in the TN population } \\
\text { (12.4\%) than in the hormonal } \\
\text { counterpart (1.01\%). However, the } \\
\text { OS rate at } 12 \text { months was lower in } \\
\text { patients with the TN phenotype, } \\
\text { being } 37.1 \% \text { vs. } 40.3 \% \text { in the other } \\
\text { phenotype } \\
\text { Patients presented moderate side } \\
\text { effects accompanied with grade } 3 \\
\text { side effects in some patients }\end{array}$ & {$[84]$} \\
\hline Durvalumab & $\begin{array}{c}\text { Patients with primary non- } \\
\text { metastatic-TNBC }\end{array}$ & $\begin{array}{c}\text { Monotherapy of intravenous } \\
\text { durvalumab }(0.75 \mathrm{~g}) 2 \text { weeks before } \\
\text { start of standard neoadjuvant } \\
\text { chemotherapy (NACT) based on } \\
\text { nab-paclitaxel followed by dose- } \\
\text { epirubicin/cyclophosphamide } \\
\text { (EC) } \\
\text { Following of intravenous } \\
\text { durvalumab } 1.5 \mathrm{~g} \text { every } 4 \text { weeks }\end{array}$ & $\begin{array}{c}\text { Increased stromal TILs (sTILs), } \\
\text { intratumoral TILs (iTILs), and } \\
\text { increased pretherapeutic PD-L1 } \\
\text { expression in tumor cells } \\
\text { Pathological complete response } \\
\text { (pCR) rate with durvalumab plus } \\
\text { NACT was 58\% vs. placebo } 44.4 \% \\
\text { Importantly, patients presented } \\
\text { thyroid dysfunction as a major side } \\
\text { effect }\end{array}$ & {$[90]$} \\
\hline
\end{tabular}


TABle 1: Continued.

\begin{tabular}{|c|c|c|c|c|}
\hline Inhibitor & Population of study & Treatment scheme & $\begin{array}{l}\text { Outstanding results/response rates } \\
\text { to therapy }\end{array}$ & References \\
\hline & & $\begin{array}{c}\text { plus nab-paclitaxel } 125 \mathrm{mg} / \mathrm{m}^{2} \\
\text { weekly for } 12 \text { weeks }\end{array}$ & & \\
\hline \multicolumn{5}{|l|}{ PD-1 inhibitors } \\
\hline Pembrolizumab & Patients with early TNBC & $\begin{array}{l}\text { Pembrolizumab alone (200 mg) or } \\
\text { pembrolizumab plus, paclitaxel } \\
\text { and carboplatin for } 3 \text { weeks. Both } \\
\text { groups were later complemented } \\
\text { with doxorubicin- } \\
\text { cyclophosphamide or epirubicin- } \\
\text { cyclophosphamide }\end{array}$ & $\begin{array}{c}\text { Side effect was grade } 3 \\
\text { The pCR was } 64.8 \% \text { in the } \\
\text { pembrolizumab-chemotherapy } \\
\text { and } 51.2 \% \text { in the placebo- } \\
\text { chemotherapy group } \\
\text { Patients showed side effects grade } 3\end{array}$ & {$[95]$} \\
\hline Pembrolizumab & Patients with mTNBC & $\begin{array}{c}\text { Intravenous pembrolizumab } \\
(200 \mathrm{mg}) \text { every } 3 \text { weeks for up to } 2 \\
\text { years }\end{array}$ & $\begin{array}{c}\text { The activity of pembrolizumab was } \\
\text { compared between PD-L1-positive } \\
\text { and PD-L1-negative women } \\
\text { The median OS was } 9.0 \text { months in } \\
\text { all patients } \\
\text { The ORR of the pembrolizumab } \\
\text { monotherapy for PD-L1-positive } \\
\text { tumors was } 5.7 \% \text { vs. } 4.7 \% \text { for } \\
\text { patients with PD-L1-negative } \\
\text { tumors } \\
\text { The PFS for PD-L1-positive } \\
\text { tumors were } 8.7 \% \text { vs. } 7.3 \% \text { in PD- } \\
\text { L1-negative tumors } \\
\text { Pembrolizumab monotherapy } \\
\text { demonstrated durable antitumor } \\
\text { activity in patients with mTNBC } \\
\text { There were no responses in } \\
\text { patients with liver metastases } \\
\text { Side effects on some patients were } \\
\text { grades } 3 \text { and } 4\end{array}$ & {$[96]$} \\
\hline Pembrolizumab & Patients with advanced TNBC & $\begin{array}{l}\text { Single-agent pembrolizumab given } \\
\text { intravenously at } 10 \mathrm{mg} / \mathrm{kg} \text { every } 2 \\
\text { weeks until completing } 36 \text { doses }\end{array}$ & $\begin{array}{c}\text { The patients experienced a } \\
\text { decrease from baseline in tumor } \\
\text { burden and the decrease was } \\
\text { maintained during all of the time of } \\
\text { study } \\
\text { Some patients showed an increase } \\
\text { in the serum levels of LDH which } \\
\text { was associated with the poor } \\
\text { response of pembrolizumab } \\
\text { The overall response rate was } \\
18.5 \% \\
\text { The major side effects found in } \\
\text { patients were arthralgia, fatigue, } \\
\text { myalgia, and nausea and some } \\
\text { grade } 3 \text { side effects }\end{array}$ & [97] \\
\hline Pembrolizumab & Patients in early-stage TNBC & $\begin{array}{l}\text { Intravenous pembrolizumab } \\
\text { (200 mg) plus chemotherapy (with } \\
\text { taxane with or without } \\
\text { carboplatin) for } 12 \text { weeks and then } \\
\text { doxorubicin and } \\
\text { cyclophosphamide for an } \\
\text { additional } 12 \text { weeks before surgery } \\
\text { ( } 6 \text { different cohorts) }\end{array}$ & $\begin{array}{c}\text { The number of TILs were higher in } \\
\text { patients with a positive expression } \\
\text { of PD-L1 } \\
\text { The study showed promising } \\
\text { antitumor activity as demonstrated } \\
\text { by the high pCR rates around } 60 \% \\
\text { across all cohorts } \\
\text { The overall survival in all of the } \\
\text { cohorts was around } 10-18 \% \text { higher } \\
\text { when a combined treatment was } \\
\text { administrated compared with } \\
\text { treatment alone }\end{array}$ & {$[98]$} \\
\hline
\end{tabular}


TABle 1: Continued.

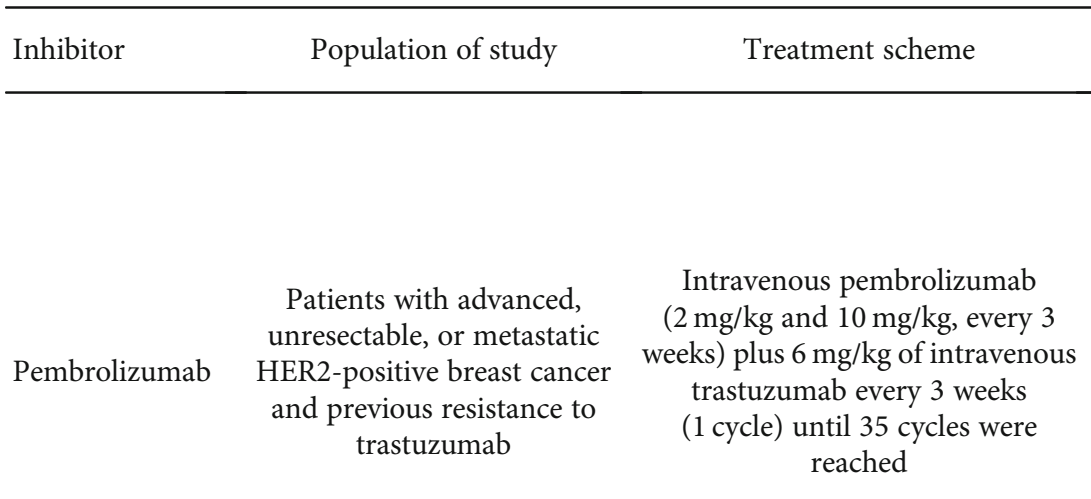

Outstanding results/response rates

References

Neutropenia was the most common side effect

The combined treatment in the

PD-L1-positive cohort had the following results: PFS was 6-12months; the PD-L1 negative cohort had 2.5 months of PFS. However, there were no objective responses, and no patient achieved control of the disease

Some patients showed grade 3 to 5 side effects. Neutropenia was the most common side effect

The study compared the PFS and

OS rates between patients with TN and ER+ phenotypes

The median PSF and the median

OS in TN patients were 4 and 15.3 months, respectively, vs. 5.1

months and were not significantly different compared with the hormone-positive phenotype

Patients with TN and hormone receptor (HR) positive/HER2 negative endocrine-refractory metastatic breast cancer

Pembrolizumab

Pembrolizumab

Patients with $\mathrm{HR}+/ \mathrm{HER} 2$ metastatic breast cancer

Patients with mTNBC patients

Nivolumab
Intravenous pembrolizumab

$(200 \mathrm{mg})$ and capecitabine $\left(1000 \mathrm{mg} / \mathrm{m}^{2}\right)$ on days $1-14$ of a 21-day cycle

Intravenous pembrolizumab $\left(200 \mathrm{mg} / \mathrm{m}^{2}\right)$ epirubicin $\left(1.4 \mathrm{mg} / \mathrm{m}^{2}\right)$ intravenously

Intravenous pembrolizumab $(200 \mathrm{mg})$ combined with radiotherapy (3000 cGy).

Intravenous nivolumab $(1 \mathrm{mg} / \mathrm{kg})$ plus ipilimumab $(1 \mathrm{mg} / \mathrm{kg})$ every 3 weeks for 4 doses followed by nivolumab $3 \mathrm{mg} / \mathrm{kg}$ every 2 weeks
The study also evaluated the effects of the combined treatment in patients with PD-L1-positive or PD-L1 negative expression. The clinical benefit rate was $33.3 \%$ in the PD-L1-positive population vs. $22.32 \%$ found in the negative counterpart

Most common adverse events were low grade and consistent with those seen in patients with a metastatic disease that received capecitabine alone, including hand-foot syndrome, gastrointestinal symptoms, fatigue, and cytopenia

The PFS and ORR were not different between the patients that received the combined treatment or the treatment alone, being PFS 4.1 vs. 4.2 months, respectively, and the ORR $25 \%$ vs. $34 \%$, respectively. Of note, all of patients were $\mathrm{PD}-\mathrm{L} 1$ positive

The combination of epirubicin and pembrolizumab was not associated with longer PFS compared with epirubicin alone

The studies are ongoing

The studies are ongoing, although better antitumor results than the treatment alone has been observed
NCT02730130 
TABLE 1: Continued.

\begin{tabular}{|c|c|c|c|c|}
\hline Inhibitor & Population of study & Treatment scheme & $\begin{array}{l}\text { Outstanding results/response rates } \\
\text { to therapy }\end{array}$ & References \\
\hline & & $\begin{array}{l}\text { until documented disease } \\
\text { progression }\end{array}$ & & \\
\hline Nivolumab & Patients with TNBC & $\begin{array}{c}\text { Intravenous nivolumab given every } \\
4 \text { weeks and cabozantinib given } \\
\text { orally once daily }\end{array}$ & The studies are ongoing & NCT03316586 \\
\hline Nivolumab & Patients with mTNBC & $\begin{array}{l}\text { Each patient was administered } \\
\text { with intravenous nivolumab } \\
(3 \mathrm{mg} / \mathrm{kg}) \text { plus radiotherapy ( } 20 \mathrm{~Gy} \\
\text { to metastatic lesion) doxorrubicin } \\
(15 \mathrm{mg}) \text { once weekly for } 2 \text { weeks, } \\
\text { cyclophosphamide }(50 \mathrm{mg}) \text { daily, } \\
\text { and cisplatin }\left(40 \mathrm{mg} / \mathrm{m}^{2}\right) \text { weekly, } \\
\text { respectively, for } 2 \text { weeks }\end{array}$ & The studies are ongoing & NCT02499367 \\
\hline
\end{tabular}

mTN: metastatic triple negative; ORR: objective response rate; OS: overall survival; pCR: pathological complete response; PFS: progression-free survival; TN: triple negative; TNBC: triple-negative breast cancer.

trials in patients with early and metastatic TNBC, showing a better duration of the antitumor response with a pathological complete response (defined as no invasive cancer in the breast and negative nodes) than in patients without treatment. Pembrolizumab has been well tolerated in patients, showing acceptable safety and manageable profile [95-97]. This drug has also been clinically evaluated in patients with early TNBC in combination with neoadjuvant chemotherapy (doxorubicin-cyclophosphamide or epirubicin-cyclophosphamide) or in metastatic TNBC in combination with anthracycline plus taxane therapy, giving a promising antitumor activity with manageable toxicity [98]. In addition, pembrolizumab has also been combined with trastuzumab, which is a monoclonal antibody considered the first-line therapy for breast cancer patients with overexpression of HER2 protein [99]. The combination of two immunotherapies was assessed in HER2+ breast cancer patients resistant to trastuzumab. The addition of pembrolizumab to trastuzumab showed tolerable side effects coupled with a higher percentage of progression-free survival (PFS) as compared with treatment alone in women with advanced disease. It is important to highlight that the authors emphasized that the improvement of this combined therapy was due to the positive expression of PD-L1 on breast cancer cells and TILs [100]. Conversely, the combination of pembrolizumab with chemotherapy (capecitabine/eribulin mesylate) in patients with a luminal breast cancer phenotype does not improve PFS [101, 102]. Thus, further studies are needed to identify molecular biomarkers to select patients who would most likely benefit from PD-1/PD-L1 checkpoint immunotherapies.

On the other hand, similarly to atezolizumab, pembrolizumab has no effects in patients with elevated serum LDH levels, visceral disease, and a high number of metastatic sites in particular in the liver [96, 97]. The aforementioned phenomenon, possibly attributed to a reduced T CD8+ cell density into the tumor, has also been observed with the use of pembrolizumab in other types of neoplasms [103]. Pembrolizumab has also been combined with radiotherapy in metastatic TNBC patients (NCT02730130). At the moment, however, potential biological markers associated with thera- peutic success of the clinical efficacy of pembrolizumab alone or in combination have not been found [104].

5.2. Nivolumab. Nivolumab is an anti-PD-1 antibody widely studied in the therapeutic practice for patients with melanoma or with metastatic NSCLC after failure of prior chemotherapy based on platinated compounds. Nivolumab treatment has exhibited different side effects after its administration in patients with NSCLC [105]. However, the clinical outcome of nivolumab seems to be good, even after the interruption of its administration in patients with NSCLC. Different comorbidities, such as hypertension and diabetes, have also been associated with patients receiving the PD-1 inhibitor [106]. In patients with TNBC, clinical studies are still ongoing. The effect of nivolumab plus ipilimumab (an anticytotoxic T-lymphocyte antigen 4 (CTLA-4) antibody) vs. nivolumab alone has been evaluated in patients with TNBC. In this study, the combined treatment showed better antitumor results than the treatment alone (NCT01928394). However, a greater toxicity also has been observed after the coadministration. Additionally, nivolumab has also been combined with cabozantinib (a small molecule inhibitor of the tyrosine kinases c-Met and VEGFR2) in treating patients with metastatic TNBC. Nevertheless, the results to date remain inconclusive (NCT03316586). At present, studies about the combination of nivolumab with radiotherapy are also under clinical investigation in patients with metastatic TNBC (NCT02499367). In the same way as the aforementioned PD-1/PD-L1 therapies, no new biological targets that limit or favor the use of nivolumab in breast cancer have been documented.

As we have been mentioning, the response to this kind of biological drug is better and widely studied in TNBC. Much of the differences have been attributed to the status of ER and HER2 expression, high tumor grade, the diversity of tumor-associated immune cells, and PD-1/PD-L1 expression. However, some studies have postulated that the selection of the patients that achieve a successful response to these drugs might fail because of methodological errors, antibody brand, or antibody clone $[67,107,108]$. In this regard, a comparison between three different antibodies (Ventana 
SP263 by Roche, Dako (22C3) pharmDx antibody, and Biocare Medical RbMCAL 10 antibody) was carried out in different biopsies derived from TNBC patients. This study describes that, although there were few discrepancies among the evaluations of PD-L1 expression in tumor cells using these clones, PD-L1 expression varied not only among tumor types but within a single tumor type at various cutoffs established by the pathologists [108]. In addition, another work also evaluated different clones of anti-PD-L1 antibodies. The authors concluded that detection of PD-L1 in TNBC cells and infiltrated immune cells from biopsies depended on the antibody clone; they found that the amount of staining was highest when using clone E1L3N, followed by clone 28-8 and clone SP142 [109]. Thus, biomarkers that reliably detect PD-L1 expression in breast cancer will increase the benefit for checkpoint immunotherapy.

\section{Epithelial-Mesenchymal Transition Factors That Determine the Efficacy of PD-1/PD-L1 Therapies in Breast Cancer}

To our knowledge, there is not a compendium of information about the biological molecules that determine the effectiveness of PD-1/PD-L1 therapies in breast cancer patients. Many studies have focused on the regulation of expression of PD-L1 in cancer. Among the mechanisms proposed are proinflammatory cytokines such as IFN- $\gamma$ and genomic and epigenetic alterations [23]. Here, we will discuss molecular factors associated with epithelial-mesenchymal transition (EMT) that might determine the effectiveness and degree of response to PD-1/PD-L1 therapies (Figure 1).

The epithelial-mesenchymal transition (EMT) is a highly dynamic process by which epithelial cells can change their characteristics into a mesenchymal phenotype. The activation of EMT supports tumor progression and metastatic expansion, as well as the generation of tumor stem cell phenotype, which play a major role in resistance to cancer treatment. Generally, EMT comprises the disruption of cell-cell adhesion, cellular polarity, remodeling of the cytoskeleton, and changes in cell-matrix adhesion [110]. It is known that not only tumor cells participate in favoring EMT, but also tumor-infiltrating immune cells, through the secretion of different soluble factors (transforming growth factor- (TGF-) $\beta$, IL-6, TNF- $\alpha$, CCL18, IFN- $\gamma$, VEGF, among others), have a positive feedback in the promotion of this process in cancer [111]. Interestingly, several pathways that have been implicated in EMT are also involved in $\mathrm{PD}-\mathrm{L} 1$ upregulation.

The hyperactivation of the PI3K/AKT pathway has also been linked with the induction of EMT in human mammary cancer cells and the upregulation of PD-L1, in addition to the expression of a well-known stem cell marker: the cluster of differentiation 44 (CD44) molecule [112]. The PI3K/AKT pathway induces PD-L1 at several levels, involving different downstream signaling pathways. The loss of two important factors of the PI3K/AKT pathway, phosphatase and tensin homolog (PTEN) and mammalian target of rapamycin (mTOR), drives the induction of PD-L1 protein levels in breast cancer cells, as well as tumor samples from breast cancer patients. The mechanism is through modulation of downstream proteins, such as S6K1 and eIF4E. In addition, deregulation of PTEN in breast cancer cells increases $\mathrm{T}$ cell apoptosis in cocultures, favoring the immune escape by tumor cells [113]. Of note, the activation of PI3K/AKT in breast cancer cells overexpressing $\mathrm{PD}-1 / \mathrm{PD}-\mathrm{L} 1$ promotes the expression of two embryonic stem cell transcriptional factors OCT4 and Nanog, which are also associated with the cancer stem cell phenotype [114]. Alternatively, different mitogenic pathways, mainly activated by growth factor receptors, induce adaptor proteins such as Crk, which in turn stabilize the active state of many receptors with or without tyrosine kinase activity through its $\mathrm{SH} 2$ and $\mathrm{SH} 3$ domains $[115,116]$. Interestingly, Crk and TGF- $\beta$ form a positive loop that promotes EMT in lung and breast cancer cells [117], see Figure 1. Cancer cells might evade antitumor immunity through EMT activation together with PD-L1 upregulation [118]. Accordingly, increased expression of Crk in cancer cells has also been associated with high PD-L1 expression in breast cancer cells; the above was observed in a syngeneic mouse model using $4 \mathrm{~T} 1$ cells [119].

The Hippo signaling pathway has also emerged as a central player in regulating many aspects of tumor biology including higher expression of oncogenes, promotion of EMT, and metastasis [120]. Accordingly, aberrant expression of transcription coactivator 1 (TAZ), a final transducer effector activated through the Hippo pathway, has recently been linked with the boost of PD-L1 levels in human breast cancer cells. The induction of PD-L1 expression was mediated by TAZ through the activation of the TEAD transcription factors with the consequent binding to the PD-L1 promoter. The activation of TAZ was also able to suppress $\mathrm{T}$ cell function and induce $\mathrm{T}$ cell apoptosis. The above was observed in cocultured TAZ-overexpressing tumor cell lines with Jurkat $\mathrm{T}$ cells previously activated with PMA (phorbol 12-myristate 13-acetate) plus PHA (phytohemagglutinin) [121]. Interestingly, the nuclear expression of TAZ has been associated with the TN phenotype in breast cancer [122].

Within the pathways that have also been linked to promoting EMT status is the WNT pathway [123]. Recently, TNBC stem cells were shown to constitutively upregulate PD-L1 through the activation of the WNT signaling pathway. Interestingly, a strong interplay between different negative regulators and final effectors of the WNT pathway together with PD-L1 expression was identified; such association was reversed using WNT inhibitors [124]. Notably, an interaction between TNBC stem cells overexpressing PD-L1 protein with $\mathrm{T}$ cells was found using confocal microscopy analysis, suggesting the presence of ineffective antitumor immunity mediated by the activation of the WNT pathway in TNBC stem cells [124]. However, the effectiveness of the $\mathrm{T}$ cell response was not evaluated.

Another important protein related to the promotion of the cancer stem cell phenotype is CD44, a transmembrane glycoprotein that is considered a homing cell adhesion molecule. CD44 plays key roles in cell proliferation, motility, and survival, being closely associated with the promotion of the EMT process [125]. The expression of CD44 in breast cancer cells can be upregulated through the activation of 

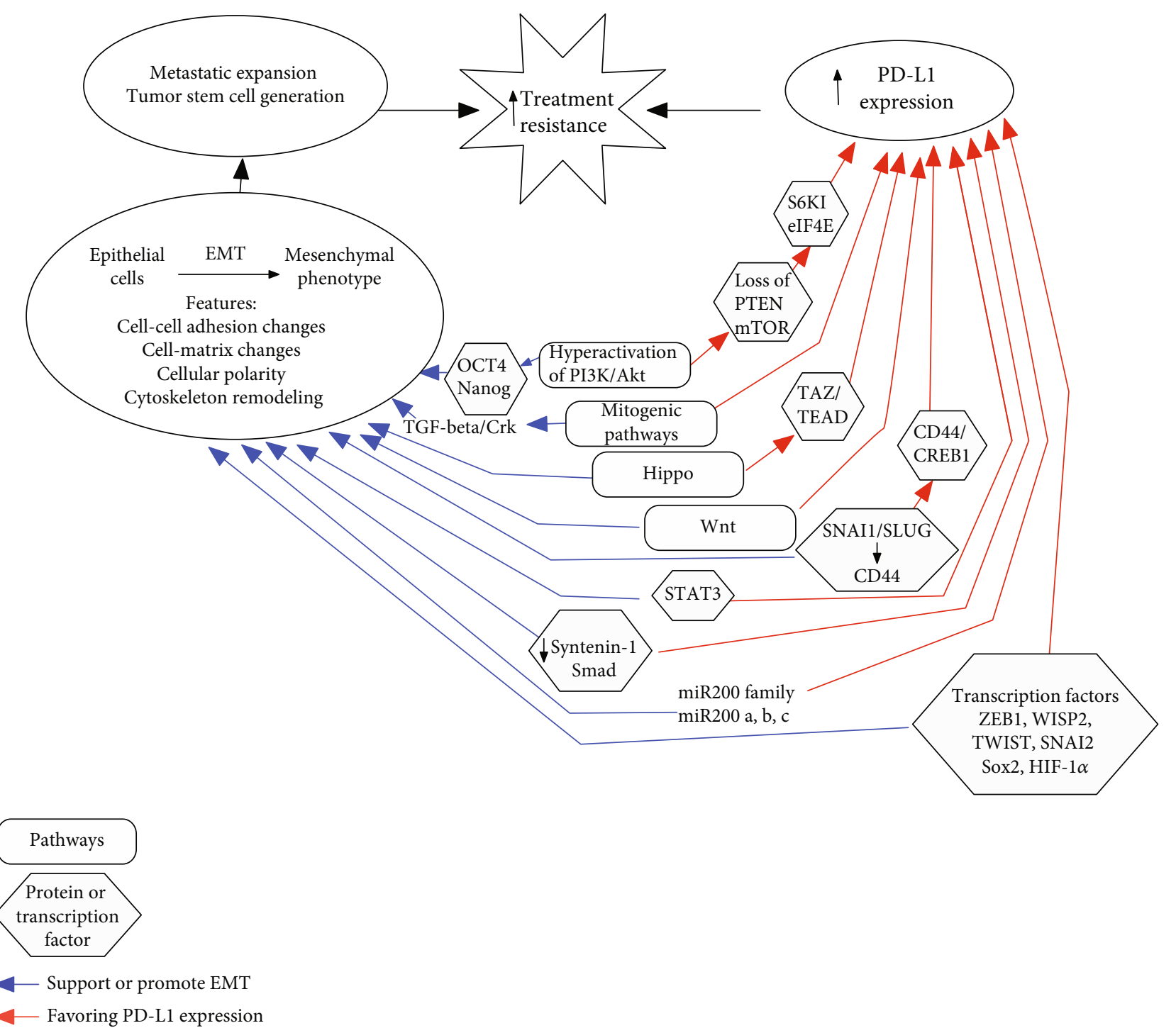

FIGURE 1: Signaling pathways and transcription factors that interconnect EMT and PD-L1 expression causing increase in PD-L1 expression and consequently failure of immune therapy in breast cancer.

different EMT-related transcription factors including SNAI1 and SLUG [126]. CD44 also participates in the switch on different pathways (AKT, STAT3, $\beta$-catenin, among others) that activate, as a final event, different mesenchymal markers promoting invasion and metastasis in breast cancer cells [127-129]. Of note, the aberrant expression of CD44 has been reported in breast cancer cells, especially in the TN phenotype, conferring poor outcome in the clinic [130, 131]. In addition, CD44 has recently been linked with the increased expression of PD-L1 in TNBC cells. The above is mediated through transcriptional regulation of $\mathrm{PD}-\mathrm{L} 1$, due to the recognition and junction of the CAMP responsive elementbinding protein 1 (CREB1) transcription factor with CD44. The above indicates that the complex CREB1-CD44 can be recruited into a specific consensus-binding sequence of the promoter of PD-L1, boosting its expression [132]. These data point out to CD44 as a critical therapeutic target to suppress the expression of PD-L1.
Signal transducer and activator of transcription 3 (STAT3) is an oncogene involved in the stem cell-like characteristics, proliferation, metastasis, and chemoresistance of breast cancer cells. In addition, activation of STAT3 can promote EMT in breast cancer cells [133]. STAT3 expressed by tumor cells induces the release of different cytokines and chemokines that interact and regulate immune components of the tumor microenvironment (TME), including $\mathrm{T}$ cells, NK cells, and tumor-associated macrophages (TAMs), giving a similar inflammatory response to that presented during the wound-healing process [134]. A positive and direct correlation between the activation of STAT3 and the increased expression of PD-L1 in breast cancer cells has been established in both human cell lines and breast cancer samples, being stronger in TNBC specimens. This phenomenon is independent of the mitogenic or proliferative actions of STAT3 $[124,135]$. Thus, the employment of STAT3 inhibitors in combination with PD-L1 blockers can be a useful 
alternative for breast cancer patients with overexpression of STAT3. This strategy is currently being carried out in clinical trials for colorectal cancer (NCT03647839).

In addition to STAT3, there are many transcription factors and miRNAs that have been closely related with the switch to EMT in breast cancer. A positive correlation between different transcription factors and the miRNA 200 family with a high score for PD-L1 expression has been established in human samples of lung adenocarcinomas and squamous lung cancers. A similar behavior has been observed in breast cancer. Overexpression of different EMT-related transcription factors in breast cancer cells has been associated with a high expression of PD-L1 [136]. Among them, different transcription factors have been reported, including twist-related protein 1 (TWIST), slug (SNAI2), snail (SNAI1), zinc finger (ZEB), sex-determining region Y-box 2 (Sox2), and the Wnt 1-inducible-signaling pathway protein 2 (WISP2) [137]. Interestingly ZEB1, WISP2, and SNAI1 but not SLUG strongly upregulate PD-L1 expression in breast cancer cells. Moreover, different members of the miR200 family (miR200a, miR200b, and miR200c) upregulate PD-L1 expression in breast cancer cells [118]. Thus, components involved with the activation of EMT can act differentially in order to upregulate the expression of PD-L1 in breast cancer cells, see Figure 1.

Hypoxia inducible factor- (HIF-) $1 \alpha$ is another factor involved in both the promotion of EMT and the regulation of PD-L1 expression. In fact, PD-L1 has hypoxia-response elements (HRE) located in the proximal PD-L1 promoter; this phenomenon was reported in myeloid-derived suppressor cells (MDSCs) [138]. Moreover, in TNBC cell lines, the increased expression of PD-L1 has also been observed after exposure to hypoxic conditions. The low levels of oxygen in cell cultures also favored apoptosis of T cells after coincubation with breast cancer cells exposed to a hypoxic environment, thus confirming a direct relationship between HIF- $1 \alpha$ and PD-L1 [139].

Syntenin-1 (syndecan-binding protein, SDCBP), also known as melanoma differentiation-associated gene-9 (MDA9), participates in the induction of the EMT process by positively regulating Smad activation, mediated by TGF- $\beta 1$ [140]. In addition, syntenin- 1 also causes the upregulation of the expression of PD-L1 in breast cancer cells [141]. Syntenin-1 is a PDZ domain-containing molecule, which was identified as a key oncogene in melanoma. Moreover, different types of cancer, including glioblastoma; neuroblastoma; and prostate, breast, and liver cancer exhibit aberrant expression of syntenin-1 [142]. Recent findings demonstrated that, through phosphorylation of STAT3, syntenin-1 increases the expression of PD-L1 in both breast cancer cell lines and in tumor tissues derived from patients with TNBC cocultured with T CD8+ cells. Thus, syntenin-1 induces $\mathrm{CD} 8+\mathrm{T}$ cell apoptosis in vitro and in vivo by upregulating PD-L1 [141].

Overall, the mechanisms reported above support the need to look for a pan-cancer EMT signature in patients with TNBC, which would lead to implement current inhibitors for the EMT players [143] in order to warrant the success of PD1/PD-L1 therapies.

\section{Metabolism-Associated Mechanisms Support PD-1/PD-L1 Signaling Favoring Tumoral Escape}

In clinical studies, strong PD-L1 expression has been significantly associated with increased risk of recurrence along with increased uptake of a glucose analogue (18F-fluorodeoxyglucose) in TNBC patients [144]. However, the relationship between increased glycolysis and the expression of PD-L1 in TNBC tumors is not clear [144]. Conversely, different PD-1/PD-L1 therapies have been reported to be ineffective against breast tumors with increased serum LDH levels (Figure 2). Therefore, modulation of the environment triggered by tumor reprogramming affects the clinical outcome of PD-1/PD-L1 therapies [22, 76, 96, 97].

An outstanding finding involving metabolic changes is that PD-1/PD-L1 signaling can shift T cell metabolism away from aerobic glycolysis and glutaminolysis, reducing the glycolytic intermediates, as well as consumption of glutamine (Figure 2). Moreover, activation of the PD-1/PD-L1 pathway forces the $\mathrm{T}$ cell to utilize alternative substrates to feed the tricarboxylic acid (TCA) cycle. In addition, the engagement of PD-L1 with its receptor blocks the nucleoside phosphate de novo synthesis in T cells [145]. The above has been observed by sophisticated metabolomic assays, where human PBMCs were cultured to expand an activate the $\mathrm{T}$ cell lineage and further treated with a recombinant human $\mathrm{Fc}$-tagged $\mathrm{PD}$ L1 fragment. Finally, different metabolites were obtained and analyzed by mass spectroscopy in order to offer a metabolite profile encompassing around 155 polar and semipolar metabolites [145]. Thus, several authors have postulated that it may be advantageous to conjugate immune-checkpoint blockade with metabolic interventions. In fact, high glucose consumption together with competition for key amino acids by tumor cells can leave $\mathrm{T}$ cells with insufficient energy and biosynthetic precursors to support activities, such as cytokine secretion. Thus, T cells are rendered dysfunctional [146]. A futuristic view could also include metabolic reinforcement with the help of cell engineering in cytotoxic T cells, such as chimeric antigen receptor T cells (CAR T cells). Thus, metabolic engineering of CAR $\mathrm{T}$ cells alongside checkpoint immunotherapy might improve clinical outcomes in breast cancer patients.

Posttranslational modification of PD-L1 such as glycosylation, phosphorylation, ubiquitination, deubiquitination, and lysosomal degradation supports the generation of resistance to PD-L1 therapies [147]. For instance, glycosylation of PDL1 protects the protein from degradation in stem, as well as non-stem breast cancer cells, suppressing the cytotoxic activity of T cells [148]. One of the mechanisms described, by which the glycosylation of PD-L1 can be achieved in breast cancer cells, involves the activation of the epidermal growth factor receptor (EGFR) signaling through binding of the epidermal growth factor (EGF) and the concomitant overactivation of the $\beta-1,3-\mathrm{N}$-acetylglucosaminyl transferase (B3GNT3) [149]. The aforementioned results suggest that EGFR signaling participates not only in the metabolic changes in breast cancer cells but also in their promotion into an EMT phenotype as it 


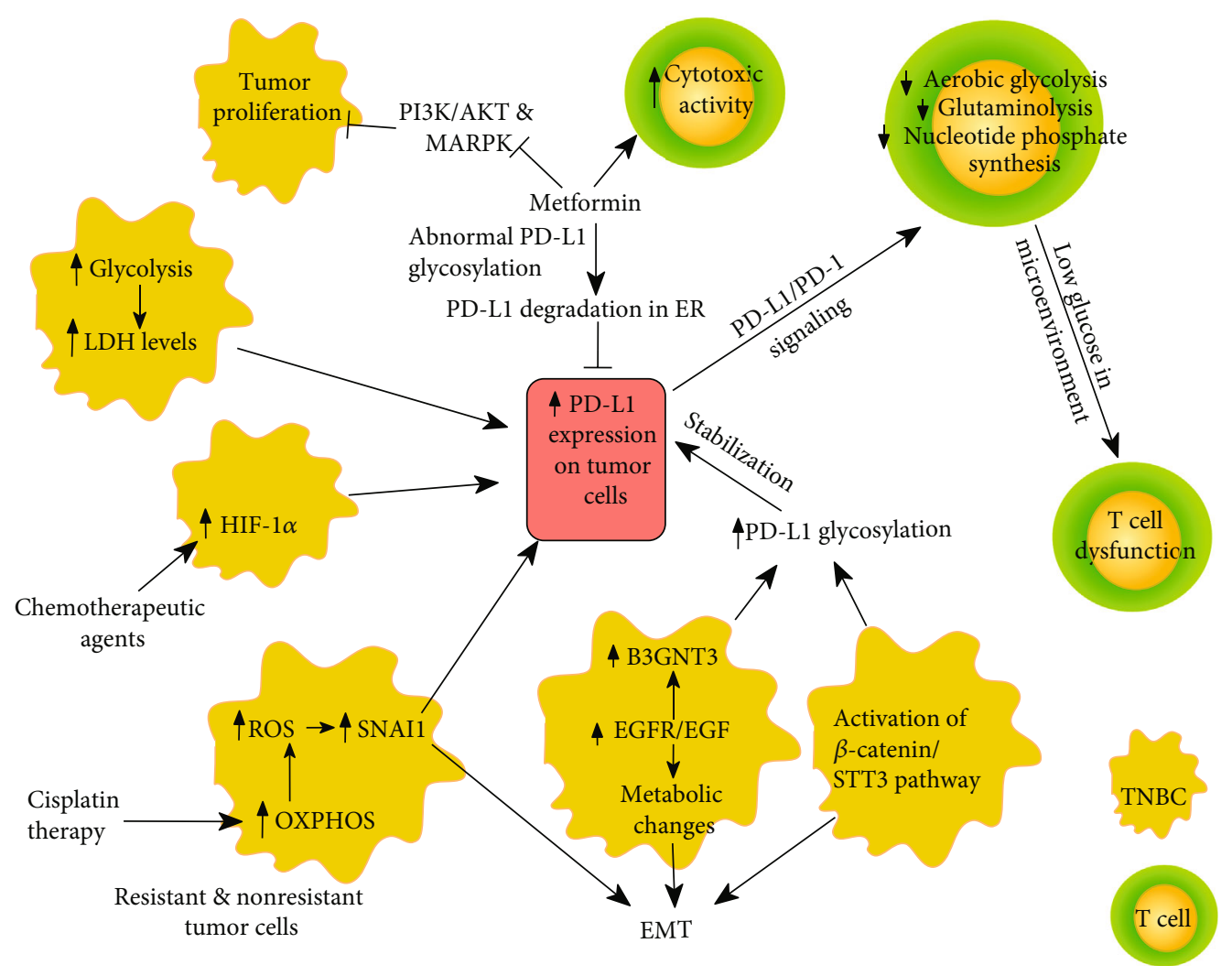

FIgURE 2: Metabolism-associated mechanisms supporting PD-L1 expression in breast cancer tumors.

has been already reported. The latter study reinforces the idea that EGFR signaling not only promotes the EMT phenotype but also participates in the metabolic changes in breast cancer cells [150]. Another mechanism that supports the glycosylation of PD-L1 in breast cancer stem cells is the activation of the EMT/ $\beta$-catenin/STT3/PD-L1 signaling axis. Interestingly, the activation of this axis activates $\mathrm{N}$-glycosyltransferase STT3, the enzyme responsible for this posttranslational modification, which leads to subsequent PD-L1 stabilization, upregulation, and consequent immune evasion [151]. Of note, STT3 is also closely associated with the maintenance of the EMT process [152].

Thus, we propose that the combination of EMT inhibitors with antibodies against glycosylated forms of PD-L1 will improve the therapeutic outcome of $\mathrm{PD}-1 / \mathrm{PD}-\mathrm{L} 1$ therapies in patients with breast cancer, specifically with the TN phenotype.

Additionally, some drugs can affect both the cell metabolism and the expression of PD-L1. Metformin, a drug linked with the regulation of the glucose metabolism in patients with diabetes type 2 , has been shown to impulse the tumor surveillance through the maintenance of induction of effector/memory CD8+ T cells [153]. Metformin reduces the proliferation of tumor cells by inhibiting PI3K/AKT and MAPK pathways [154]. Metformin also decreases PD-L1 levels through inducing abnormal PD-L1 glycosylation with Man9GlcNAc2, a rare glycan structure, which results in its degradation in the endoplasmic reticulum in breast cancer cells [155-157], see Figure 2. In addition, metformin regulates the secretion of different proinflammatory cytokines, including IL- $1 \beta$, IL-6, IFN- $\gamma$, and TNF- $\alpha$. This phenomenon leads to the attenuation of the inflammatory process in cancer, thus promoting the antitumor immune response $[156,158$, 159]. Hence, metformin might be used as a new regulator of the expression of PD-L1 in combination with PD-1/PDL1 target therapies.

It is widely known that TNBC tumors lack a target therapy. For this reason, they are treated with cytotoxic therapy [160]. In this sense, the neoadjuvant chemotherapy (NAC) based on cisplatin also induces resistance in TNBC [161]. Interestingly, the conventional treatment of cisplatin in NSCLC has been shown to induce drug resistance through the alteration of tumor metabolism [162]. Therefore, cisplatin-resistant cells become more reliant on mitochondria oxidative metabolism mediated by the production of reactive oxygen species (ROS) instead of glucose metabolism [163, 164]. On the other hand, high ROS levels, along with metabolic alterations, contribute to the EMT process through the activation of the transcription factor SNAI1 in breast cancer cells [165] (Figure 2). Treatment with cisplatin and the subsequent generation of cisplatin-resistant breast cancer cells might also induce PD-L1 expression in breast cancer; nonetheless, this statement has not been fully addressed [166].

Interestingly, NAC not only may impact on the metabolic pathways of cancer cells, but it may also affect the number of immune cells recruited into the tumor microenvironment or in circulation [167]. For instance, in breast cancer patients with the TN phenotype, the administration of NAC based 
on anthracycline or taxane modified the infiltration of the neutrophil ratio [168], which has been associated with a proinflammatory profile that favors poor patient survival outcomes in early and advanced TNBC [169]. Nonetheless, unconvincing results about the modulation of the expression of PD-L1 in the breast cancer cells were reported [168].

Other chemotherapeutic agents including carboplatin, doxorubicin, gemcitabine, or paclitaxel have also been shown to induce the expression of PD-L1 in TNBC cells through a HIF-1 $\alpha$-dependent transcriptional mechanism [170], see Figure 2. In addition, coculture of breast cancer cells, treated with these chemotherapeutic drugs, with activated T CD8+ cells under hypoxic conditions, results in the inhibition of $\mathrm{T}$ cell activity and CD8+ $\mathrm{T}$ cell apoptosis [170]. This again suggests that chemotherapy induces important metabolic changes that impact in the expression of PD-L1, which eventually would lead to the evasion of the immune system.

\section{Conclusion}

We have reviewed pathways, transcription factors, as well as molecules that interconnect EMT with PD-L1 expression, hence supporting treatment resistance in TNBC. Among the variables that should be taken into account for increasing the success of antitumor therapies based on immune checkpoints, metabolism-associated mechanisms promoting PD-L1 expression, alongside with postranslational mechanisms that stabilize PD-L1 structure, must be considered. We suggest that PD-1/PD-L1 checkpoint therapies could be greatly improved in TNBC with the employment of inhibitors of EMT and metabolic reprogramming of CAR T cell therapies, as well as the avoidance of the combination of PD-1/PD-L1 therapies with chemotherapeutic agents. The use of mathematical models that incorporate tumor-immune cell dynamics might provide quantitative representations of the phenomena involved in cancer progression [171]. This approach would be useful to mimic molecular networks and to search for novel networks. Consequently, a more comprehensive knowledge would be obtained concerning the interaction among EMT, metabolic reprogramming, epigenetic modifications, and drug interactions, which, all together, govern PD-L1 expression in breast cancer.

\section{Data Availability}

No data were used to support this study.

\section{Conflicts of Interest}

The authors declare that they have no competing financial interests or personal relationships that influence the work reported in this paper.

\section{Acknowledgments}

The authors acknowledge Instituto Nacional de Enfermedades Respiratorias Ismael Cosio Villegas for supporting the publication of this manuscript.

\section{References}

[1] N. Harbeck, F. Penault-Llorca, J. Cortes et al., "Breast cancer," Nature Reviews. Disease Primers, vol. 5, no. 1, 2019.

[2] Y. Feng, M. Spezia, S. Huang et al., "Breast cancer development and progression: risk factors, cancer stem cells, signaling pathways, genomics, and molecular pathogenesis," Genes \& Diseases, vol. 5, no. 2, pp. 77-106, 2018.

[3] A. Tremont, J. Lu, and J. T. Cole, "Endocrine therapy for early breast cancer: updated review," The Ochsner Journal, vol. 17, no. 4, pp. 405-411, 2017.

[4] M. Segovia-Mendoza, M. E. González-González, D. Barrera, L. Díaz, and R. García-Becerra, "Efficacy and mechanism of action of the tyrosine kinase inhibitors gefitinib, lapatinib and neratinib in the treatment of HER2-positive breast cancer: preclinical and clinical evidence," American Journal of Cancer Research, vol. 5, no. 9, pp. 2531-2561, 2015.

[5] M. C. Cheang, D. Voduc, C. Bajdik et al., "Basal-like breast cancer defined by five biomarkers has superior prognostic value than triple-negative phenotype," Clinical Cancer Research, vol. 14, no. 5, pp. 1368-1376, 2008.

[6] J. Mehanna, F. G. Haddad, R. Eid, M. Lambertini, and H. R. Kourie, "Triple-negative breast cancer: current perspective on the evolving therapeutic landscape," International Journal of Women's Health, vol. 11, pp. 431-437, 2019.

[7] T. O. Nielsen, F. D. Hsu, K. Jensen et al., "Immunohistochemical and clinical characterization of the basal-like subtype of invasive breast carcinoma," Clinical Cancer Research, vol. 10, no. 16, pp. 5367-5374, 2004.

[8] S. G. Ahn, S. J. Kim, C. Kim, and J. Jeong, "Molecular classification of triple-negative breast cancer," Journal of Breast Cancer, vol. 19, no. 3, pp. 223-230, 2016.

[9] A. Zgura, L. Galesa, E. Bratila, and R. Anghel, "Relationship between tumor infiltrating lymphocytes and progression in breast cancer," Maedica, vol. 13, no. 4, pp. 317-320, 2018.

[10] M. Segovia-Mendoza and J. Morales-Montor, "Immune tumor microenvironment in breast cancer and the participation of estrogen and its receptors in cancer physiopathology," Frontiers in Immunology, vol. 10, 2019.

[11] R. S. Herbst, J. C. Soria, M. Kowanetz et al., "Predictive correlates of response to the anti-PD-L1 antibody MPDL3280A in cancer patients," Nature, vol. 515, no. 7528, pp. 563-567, 2014.

[12] J. M. Taube, A. Klein, J. R. Brahmer et al., "Association of PD1, PD-1 ligands, and other features of the tumor immune microenvironment with response to anti-PD-1 therapy," Clinical Cancer Research, vol. 20, no. 19, pp. 5064-5074, 2014.

[13] L. Chen and D. B. Flies, "Molecular mechanisms of T cell costimulation and co-inhibition," Nature Reviews. Immunology, vol. 13, no. 4, pp. 227-242, 2013.

[14] H. O. Alsaab, S. Sau, R. Alzhrani et al., "PD-1 and PD-L1 checkpoint signaling inhibition for cancer immunotherapy: mechanism, combinations, and clinical outcome," Frontiers in Pharmacology, vol. 8, 2017.

[15] N. Y. Sun, Y. L. Chen, W. Y. Wu et al., "Blockade of PD-L1 enhances cancer immunotherapy by regulating dendritic cell maturation and macrophage polarization," Cancers, vol. 11, no. 9, 2019.

[16] S. Chen, G. A. Crabill, T. S. Pritchard et al., "Mechanisms regulating PD-L1 expression on tumor and immune cells," Journal for Immunotherapy of Cancer, vol. 7, no. 1, 2019. 
[17] T. Yamazaki, H. Akiba, H. Iwai et al., "Expression of programmed death 1 ligands by murine T cells and APC," Journal of Immunology, vol. 169, no. 10, pp. 5538-5545, 2002.

[18] J. Konishi, K. Yamazaki, M. Azuma, I. Kinoshita, H. DosakaAkita, and M. Nishimura, "B7-H1 expression on non-small cell lung cancer cells and its relationship with tumorinfiltrating lymphocytes and their PD-1 expression," Clinical Cancer Research, vol. 10, no. 15, pp. 5094-5100, 2004.

[19] P. Ritprajak and M. Azuma, "Intrinsic and extrinsic control of expression of the immunoregulatory molecule PD-L1 in epithelial cells and squamous cell carcinoma," Oral Oncology, vol. 51, no. 3, pp. 221-228, 2015.

[20] Y. Qian, J. Deng, L. Geng et al., “TLR4 signaling induces B7H1 expression through MAPK pathways in bladder cancer cells," Cancer Investigation, vol. 26, no. 8, pp. 816-821, 2008.

[21] A. Garcia-Diaz, D. S. Shin, B. H. Moreno et al., "Interferon receptor signaling pathways regulating $\mathrm{PD}-\mathrm{L} 1$ and $\mathrm{PD}-\mathrm{L} 2$ expression," Cell Reports, vol. 19, no. 6, pp. 1189-1201, 2017.

[22] L. A. Emens, C. Cruz, J. P. Eder et al., "Long-term clinical outcomes and biomarker analyses of atezolizumab therapy for patients with metastatic triple-negative breast cancer: a phase 1 study," JAMA Oncology, vol. 5, no. 1, pp. 74-82, 2019.

[23] J. H. Cha, L. C. Chan, C. W. Li, J. L. Hsu, and M. C. Hung, "Mechanisms controlling PD-L1 expression in cancer," Molecular Cell, vol. 76, no. 3, pp. 359-370, 2019.

[24] A. J. Schoenfeld, H. Rizvi, C. Bandlamudi et al., "Clinical and molecular correlates of PD-L1 expression in patients with lung adenocarcinomas ${ }^{\text {is }}$," Annals of Oncology, vol. 31, no. 5, pp. 599-608, 2020.

[25] M. Albitar, S. Sudarsanam, W. Ma et al., "Correlation of MET gene amplification and TP53 mutation with PD-L1 expression in non-small cell lung cancer," Oncotarget, vol. 9, no. 17, article 24455, pp. 13682-13693, 2018.

[26] N. Chen, W. Fang, Z. Lin et al., "KRAS mutation-induced upregulation of PD-L1 mediates immune escape in human lung adenocarcinoma," Cancer Immunology, Immunotherapy, vol. 66, no. 9, article 2005, pp. 1175-1187, 2017.

[27] J. J. el-Jawhari, Y. M. el-Sherbiny, G. B. Scott et al., "Blocking oncogenic RAS enhances tumour cell surface MHC class I expression but does not alter susceptibility to cytotoxic lymphocytes," Molecular Immunology, vol. 58, no. 2, pp. 160168, 2014.

[28] M. A. Coelho, S. de Carné Trécesson, S. Rana et al., "Oncogenic RAS signaling promotes tumor immunoresistance by stabilizing PD-L1 mRNA," Immunity, vol. 47, no. 6, pp. 1083-1099.e6, 2017.

[29] H. Zhu, F. Bengsch, N. Svoronos et al., "BET bromodomain inhibition promotes anti-tumor immunity by suppressing PD-L1 expression," Cell Reports, vol. 16, no. 11, pp. 28292837, 2016.

[30] A. Alqahtani, K. Choucair, M. Ashraf et al., "Bromodomain and extra-terminal motif inhibitors: a review of preclinical and clinical advances in cancer therapy," Future science $O A$, vol. 5, no. 3, article FSO372, 2019.

[31] G. P. Andrieu, J. S. Shafran, C. L. Smith et al., "BET protein targeting suppresses the PD-1/PD-L1 pathway in triplenegative breast cancer and elicits anti-tumor immune response," Cancer Letters, vol. 465, pp. 45-58, 2019.

[32] X. Jing, S. Shao, Y. Zhang et al., "BRD4 inhibition suppresses PD-L1 expression in triple-negative breast cancer," Experimental Cell Research, vol. 392, no. 2, article 112034, 2020.
[33] X. Shen, L. Zhang, J. Li, Y. Li, Y. Wang, and Z. X. Xu, "Recent findings in the regulation of programmed death ligand 1 expression," Frontiers in Immunology, vol. 10, 2019.

[34] L. Guo, W. Li, X. Zhu et al., "PD-L1 expression and CD274 gene alteration in triple-negative breast cancer: implication for prognostic biomarker," Springerplus, vol. 5, no. 1, article 2513, 2016.

[35] M. T. Barrett, K. S. Anderson, E. Lenkiewicz et al., "Genomic amplification of 9p24.1 targeting JAK2, PD-L1, and $P D-L 2$ is enriched in high-risk triple negative breast cancer," Oncotarget, vol. 6, no. 28, pp. 26483-26493, 2015.

[36] M. Chen, B. Pockaj, M. Andreozzi et al., "JAK2 and PD-L1 amplification enhance the dynamic expression of PD-L1 in triple-negative breast cancer," Clinical Breast Cancer, vol. 18, no. 5, pp. e1205-e1215, 2018.

[37] L. Ni and J. Lu, "Interferon gamma in cancer immunotherapy," Cancer Medicine, vol. 7, no. 9, pp. 4509-4516, 2018.

[38] K. C. Ohaegbulam, A. Assal, E. Lazar-Molnar, Y. Yao, and $\mathrm{X}$. Zang, "Human cancer immunotherapy with antibodies to the PD-1 and PD-L1 pathway," Trends in Molecular Medicine, vol. 21, no. 1, pp. 24-33, 2015.

[39] Y. Han, D. Liu, and L. Li, "PD-1/PD-L1 pathway: current researches in cancer," American Journal of Cancer Research, vol. 10, no. 3, pp. 727-742, 2020.

[40] D. Sugiura, T. Maruhashi, I. M. Okazaki et al., "Restriction of $\mathrm{PD}-1$ function by cis-PD-L1/CD80 interactions is required for optimal T cell responses," Science, vol. 364, no. 6440, pp. 558-566, 2019.

[41] H. G. Ljunggren, R. Jonsson, and P. Hoglund, "Seminal immunologic discoveries with direct clinical implications: the 2018 Nobel Prize in Physiology or Medicine honours discoveries in cancer immunotherapy," Scandinavian Journal of Immunology, vol. 88, no. 6, article e12731, 2018.

[42] D. Hanahan and R. A. Weinberg, "Hallmarks of cancer: the next generation," Cell, vol. 144, no. 5, pp. 646-674, 2011.

[43] F. C. Santini and M. D. Hellmann, "PD-1/PD-L1 axis in lung cancer," Cancer Journal, vol. 24, no. 1, pp. 15-19, 2018.

[44] R. R. Munhoz and M. A. Postow, "Clinical development of PD-1 in advanced melanoma," Cancer Journal, vol. 24, no. 1, pp. 7-14, 2018.

[45] Y. Wu, W. Chen, Z. P. Xu, and W. Gu, "PD-L1 distribution and perspective for cancer immunotherapy-blockade, knockdown, or inhibition," Frontiers in Immunology, vol. 10, 2019.

[46] A. Akinleye and Z. Rasool, "Immune checkpoint inhibitors of PD-L1 as cancer therapeutics," Journal of Hematology \& Oncology, vol. 12, no. 1, 2019.

[47] Y. Zheng, Y. C. Fang, and J. Li, "PD-L1 expression levels on tumor cells affect their immunosuppressive activity," Oncology Letters, vol. 18, no. 5, pp. 5399-5407, 2019.

[48] X. Shen and B. Zhao, "Efficacy of PD-1 or PD-L1 inhibitors and PD-L1 expression status in cancer: meta-analysis," BMJ, vol. 362, 2018.

[49] M. Garcia-Aranda and M. Redondo, "Immunotherapy: a challenge of breast cancer treatment," Cancers, vol. 11, no. 12, 2019.

[50] G. Planes-Laine, P. Rochigneux, F. Bertucci et al., "PD-1/PDL1 targeting in breast cancer: the first clinical evidences are emerging. A literature review," Cancers, vol. 11, no. 7, 2019.

[51] H. Ghebeh, S. Mohammed, A. al-Omair et al., "The B7-H1 (PD-L1) T lymphocyte-inhibitory molecule is expressed in breast cancer patients with infiltrating ductal carcinoma: 
correlation with important high-risk prognostic factors," Neoplasia, vol. 8, no. 3, pp. 190-198, 2006.

[52] M. Sobral-Leite, K. van de Vijver, M. Michaut et al., "Assessment of PD-L1 expression across breast cancer molecular subtypes, in relation to mutation rate, BRCA1-like status, tumor-infiltrating immune cells and survival," OncoImmunology, vol. 7, no. 12, article e1509820, 2018.

[53] E. A. Mittendorf, A. V. Philips, F. Meric-Bernstam et al., "PDL1 expression in triple-negative breast cancer," Cancer Immunology Research, vol. 2, no. 4, pp. 361-370, 2014.

[54] H. R. Ali, S. E. Glont, F. M. Blows et al., "PD-L1 protein expression in breast cancer is rare, enriched in basal-like tumours and associated with infiltrating lymphocytes," Annals of Oncology, vol. 26, no. 7, pp. 1488-1493, 2015.

[55] R. Sabatier, P. Finetti, E. Mamessier et al., "Prognostic and predictive value of PDL1 expression in breast cancer," Oncotarget, vol. 6, no. 7, pp. 5449-5464, 2015.

[56] A. M. Alves, J. Paredes, and F. Schmitt, "Expression of PD-L1 in primary breast carcinoma and lymph node metastases," Surgical and Experimental Pathology, vol. 2, no. 1, 2019.

[57] F. Li, Y. Ren, and Z. Wang, "Programmed death 1 ligand 1 expression in breast cancer and its association with patients' clinical parameters," Journal of Cancer Research and Therapeutics, vol. 14, no. 1, pp. 150-154, 2018.

[58] R. Dogukan, R. Ucak, F. M. Dogukan, C. Tanik, B. Citgez, and F. Kabukcuoglu, "Correlation between the expression of PDL1 and clinicopathological parameters in triple negative breast cancer patients," European journal of breast health, vol. 15, no. 4, pp. 235-241, 2019.

[59] C. Yuan, Z. Liu, Q. Yu et al., "Expression of PD-1/PD-L1 in primary breast tumours and metastatic axillary lymph nodes and its correlation with clinicopathological parameters," Scientific Reports, vol. 9, no. 1, article 14356, 2019.

[60] H. Ghebeh, A. Tulbah, S. Mohammed et al., "Expression of B7-H1 in breast cancer patients is strongly associated with high proliferative Ki-67-expressing tumor cells," International Journal of Cancer, vol. 121, no. 4, pp. 751-758, 2007.

[61] Z. Evangelou, A. Papoudou-Bai, G. Karpathiou et al., "PD-L1 expression and tumor-infiltrating lymphocytes in breast cancer: clinicopathological analysis in women younger than 40 years old," In Vivo, vol. 34, no. 2, pp. 639-647, 2020.

[62] E. S. Stovgaard, M. Bokharaey, K. List-Jensen et al., "PD-L1 diagnostics in the neoadjuvant setting: implications of intratumoral heterogeneity of PD-L1 expression in triple negative breast cancer for assessment in small biopsies," Breast Cancer Research and Treatment, vol. 181, no. 3, pp. 553-560, 2020.

[63] Q. Zhai, J. Fan, Q. Lin et al., "Tumor stromal type is associated with stromal PD-L1 expression and predicts outcomes in breast cancer," PLoS One, vol. 14, no. 10, article e0223325, 2019.

[64] K. A. Schalper, V. Velcheti, D. Carvajal et al., "In situ tumor PD-L1 mRNA expression is associated with increased TILs and better outcome in breast carcinomas," Clinical Cancer Research, vol. 20, no. 10, pp. 2773-2782, 2014.

[65] Z. Liu, M. Li, Z. Jiang, and X. Wang, "A comprehensive immunologic portrait of triple-negative breast cancer," Translational Oncology, vol. 11, no. 2, pp. 311-329, 2018.

[66] J. Stagg and B. Allard, "Immunotherapeutic approaches in triple-negative breast cancer: latest research and clinical prospects," Therapeutic advances in medical oncology, vol. 5, no. 3, pp. 169-181, 2013.
[67] Z. Q. Wang, K. Milne, H. Derocher, J. R. Webb, B. H. Nelson, and P. H. Watson, "PD-L1 and intratumoral immune response in breast cancer," Oncotarget, vol. 8, no. 31, article 18305, pp. 51641-51651, 2017.

[68] C. Solinas, A. Gombos, S. Latifyan, M. Piccart-Gebhart, M. Kok, and L. Buisseret, "Targeting immune checkpoints in breast cancer: an update of early results," ESMO Open, vol. 2, no. 5, article e000255, 2017.

[69] X. Wang and Y. Liu, "PD-L1 expression in tumor infiltrated lymphocytes predicts survival in triple-negative breast cancer," Pathology, Research and Practice, vol. 216, no. 3, article 152802,2020

[70] D. Lu, Z. Ni, X. Liu et al., "Beyond T cells: understanding the role of PD-1/PD-L1 in tumor-associated macrophages," Journal of Immunology Research, vol. 2019, Article ID 1919082, 7 pages, 2019.

[71] L. Shi, S. Chen, L. Yang, and Y. Li, "The role of PD-1 and PD$\mathrm{L} 1 \mathrm{in} \mathrm{T}$-cell immune suppression in patients with hematological malignancies," Journal of Hematology \& Oncology, vol. 6, no. 1, 2013.

[72] N. Seetharamu, I. R. Preeshagul, and K. M. Sullivan, "New PD-L1 inhibitors in non-small cell lung cancer-impact of atezolizumab," Lung Cancer: Targets and Therapy, vol. 8, pp. 67-78, 2017.

[73] M. Eckstein, A. Cimadamore, A. Hartmann et al., "PD-L1 assessment in urothelial carcinoma: a practical approach," Annals of Translational Medicine, vol. 7, no. 22, 2019.

[74] B. A. Inman, T. A. Longo, S. Ramalingam, and M. R. Harrison, "Atezolizumab: a PD-L1-blocking antibody for bladder cancer," Clinical Cancer Research, vol. 23, no. 8, pp. 18861890, 2017.

[75] S. Adams, J. R. Diamond, E. Hamilton et al., "Atezolizumab plus nab-paclitaxel in the treatment of metastatic triplenegative breast cancer with 2-year survival follow-up: a phase 1 b clinical trial," JAMA Oncology, vol. 5, no. 3, pp. 334-342, 2019.

[76] V. Vafaizadeh and Z. Barekati, "Immuno-oncology biomarkers for personalized immunotherapy in breast cancer," Frontiers in Cell and Development Biology, vol. 8, 2020.

[77] P. Schmid, S. Adams, H. S. Rugo et al., "Atezolizumab and nab-paclitaxel in advanced triple-negative breast cancer," The New England Journal of Medicine, vol. 379, no. 22, pp. 2108-2121, 2018.

[78] F. S. Cyprian, S. Akhtar, Z. Gatalica, and S. Vranic, “Targeted immunotherapy with a checkpoint inhibitor in combination with chemotherapy: a new clinical paradigm in the treatment of triple-negative breast cancer," Bosnian Journal of Basic Medical Sciences, vol. 19, no. 3, pp. 227-233, 2019.

[79] D. Mishra and D. Banerjee, "Lactate dehydrogenases as metabolic links between tumor and stroma in the tumor microenvironment," Cancers, vol. 11, no. 6, 2019.

[80] A. K. Gupta, S. G. Versteeg, W. Abramovits, and K. D. Vincent, "Bavencio ${ }^{\circledR}$ (avelumab) - a newly approved anti-PDL1 IgG1 antibody," Skinmed, vol. 16, no. 3, pp. 183-187, 2018.

[81] H. L. Kaufman, J. Russell, O. Hamid et al., “Avelumab in patients with chemotherapy-refractory metastatic Merkel cell carcinoma: a multicentre, single-group, open-label, phase 2 trial," Lancet Oncology, vol. 17, no. 10, pp. 1374-1385, 2016.

[82] B. Boyerinas, C. Jochems, M. Fantini et al., "Antibody-dependent cellular cytotoxicity activity of a novel anti-PD-L1 
antibody avelumab (MSB0010718C) on human tumor cells," Cancer Immunology Research, vol. 3, no. 10, pp. 1148-1157, 2015.

[83] R. Fujii, E. R. Friedman, J. Richards et al., "Enhanced killing of chordoma cells by antibody-dependent cell-mediated cytotoxicity employing the novel anti-PD-L1 antibody avelumab," Oncotarget, vol. 7, no. 23, pp. 33498-33511, 2016.

[84] L. Y. Dirix, I. Takacs, G. Jerusalem et al., “Avelumab, an antiPD-L1 antibody, in patients with locally advanced or metastatic breast cancer: a phase 1b JAVELIN Solid Tumor study," Breast Cancer Research and Treatment, vol. 167, no. 3, pp. 671-686, 2018.

[85] J. M. Collins and J. L. Gulley, "Product review: avelumab, an anti-PD-L1 antibody," Human Vaccines \& Immunotherapeutics, vol. 15, no. 4, pp. 891-908, 2019.

[86] P. Tarantino and G. Curigliano, "Defining the immunogram of breast cancer: a focus on clinical trials," Expert Opinion on Biological Therapy, vol. 19, no. 5, pp. 383-385, 2019.

[87] T. Powles, P. H. O'Donnell, C. Massard et al., "Efficacy and safety of durvalumab in locally advanced or metastatic urothelial carcinoma: updated results from a phase $1 / 2$ open-label study," JAMA Oncology, vol. 3, no. 9, article e172411, 2017.

[88] Y. H. Kim, "Durvalumab after chemoradiotherapy in stage III non-small-cell lung cancer," The New England Journal of Medicine, vol. 380, no. 10, pp. 989-990, 2019.

[89] C. Denkert, S. Wienert, A. Poterie et al., "Standardized evaluation of tumor-infiltrating lymphocytes in breast cancer: results of the ring studies of the international immunooncology biomarker working group," Modern Pathology, vol. 29, no. 10, pp. 1155-1164, 2016.

[90] S. Loibl, M. Untch, N. Burchardi et al., "A randomised phase II study investigating durvalumab in addition to an anthracycline taxane-based neoadjuvant therapy in early triplenegative breast cancer: clinical results and biomarker analysis of GeparNuevo study," Annals of Oncology, vol. 30, no. 8, pp. 1279-1288, 2019.

[91] H. T. Lee, J. Y. Lee, H. Lim et al., "Molecular mechanism of PD-1/PD-L1 blockade via anti-PD-L1 antibodies atezolizumab and durvalumab," Scientific Reports, vol. 7, no. 1, p. 5532, 2017.

[92] K. M. Morrissey, T. M. Yuraszeck, C. C. Li, Y. Zhang, and S. Kasichayanula, "Immunotherapy and novel combinations in oncology: current landscape, challenges, and opportunities," Clinical and Translational Science, vol. 9, no. 2, pp. 89-104, 2016.

[93] R. S. Herbst, P. Baas, D. W. Kim et al., "Pembrolizumab versus docetaxel for previously treated, PD-L1-positive, advanced non-small-cell lung cancer (KEYNOTE-010): a randomised controlled trial," The Lancet, vol. 387, no. 10027, pp. 1540-1550, 2016.

[94] M. A. Postow, M. K. Callahan, and J. D. Wolchok, "Immune checkpoint blockade in cancer therapy," Journal of Clinical Oncology, vol. 33, no. 17, pp. 1974-1982, 2015.

[95] P. Schmid, J. Cortes, L. Pusztai et al., "Pembrolizumab for early triple-negative breast cancer," The New England Journal of Medicine, vol. 382, no. 9, pp. 810-821, 2020.

[96] S. Adams, P. Schmid, H. S. Rugo et al., "Pembrolizumab monotherapy for previously treated metastatic triplenegative breast cancer: cohort A of the phase II KEYNOTE-
086 study," Annals of Oncology, vol. 30, no. 3, pp. 397-404, 2019.

[97] R. Nanda, L. Q. M. Chow, E. C. Dees et al., "Pembrolizumab in patients with advanced triple-negative breast cancer: phase Ib KEYNOTE-012 study," Journal of Clinical Oncology, vol. 34, no. 21, pp. 2460-2467, 2016.

[98] P. Schmid, R. Salgado, Y. H. Park et al., "Pembrolizumab plus chemotherapy as neoadjuvant treatment of high-risk, earlystage triple-negative breast cancer: results from the phase $1 \mathrm{~b}$ open-label, multicohort KEYNOTE-173 study," Annals of Oncology, vol. 31, no. 5, pp. 569-581, 2020.

[99] J. Wang and B. Xu, "Targeted therapeutic options and future perspectives for HER2-positive breast cancer," Signal Transduction and Targeted Therapy, vol. 4, no. 1, p. 34, 2019.

[100] S. Loi, A. Giobbie-Hurder, A. Gombos et al., "Pembrolizumab plus trastuzumab in trastuzumab-resistant, advanced, HER2-positive breast cancer (PANACEA): a single-arm, multicentre, phase 1b-2 trial," The Lancet Oncology, vol. 20, no. 3, pp. 371-382, 2019.

[101] A. N. Shah, L. Flaum, I. Helenowski et al., "Phase II study of pembrolizumab and capecitabine for triple negative and hormone receptor-positive, HER2-negative endocrine-refractory metastatic breast cancer," Journal for Immunotherapy of Cancer, vol. 8, no. 1, 2019.

[102] S. M. Tolaney, R. Barroso-Sousa, T. Keenan et al., "Randomized phase II study of eribulin mesylate (E) with or without pembrolizumab $(\mathrm{P})$ for hormone receptor-positive $(\mathrm{HR}+)$ metastatic breast cancer (MBC)," Journal of Clinical Oncology, vol. 37, Supplement 15, p. 1004, 2019.

[103] P. C. Tumeh, M. D. Hellmann, O. Hamid et al., "Liver metastasis and treatment outcome with anti-PD-1 monoclonal antibody in patients with melanoma and NSCLC," Cancer Immunology Research, vol. 5, no. 5, pp. 417-424, 2017.

[104] H. L. McArthur, C. A. Barker, A. Gucalp et al., "A single-arm, phase II study assessing the efficacy of pembrolizumab (pembro) plus radiotherapy (RT) in metastatic triple negative breast cancer (mTNBC)," Journal of Clinical Oncology, vol. 36, Supplement 5, p. 14, 2018.

[105] H. Kimura, T. Araya, T. Yoneda et al., "Long-lasting responses after discontinuation of nivolumab treatment for reasons other than tumor progression in patients with previously treated, advanced non-small cell lung cancer," Cancer Communications, vol. 39, no. 1, p. 78, 2019.

[106] M. Giaj Levra, F. E. Cotté, R. Corre et al., "Immunotherapy rechallenge after nivolumab treatment in advanced nonsmall cell lung cancer in the real-world setting: a national data base analysis," Lung Cancer, vol. 140, pp. 99-106, 2020.

[107] F. Bertucci and A. Goncalves, "Immunotherapy in breast cancer: the emerging role of PD-1 and PD-L1," Current Oncology Reports, vol. 19, no. 10, p. 64, 2017.

[108] T. Karnik, B. F. Kimler, F. Fan, and O. Tawfik, "PD-L1 in breast cancer: comparative analysis of 3 different antibodies," Human Pathology, vol. 72, pp. 28-34, 2018.

[109] W. Y. Sun, Y. K. Lee, and J. S. Koo, "Expression of PD-L1 in triple-negative breast cancer based on different immunohistochemical antibodies," Journal of Translational Medicine, vol. 14, no. 1, p. 173, 2016.

[110] M. Fedele, L. Cerchia, and G. Chiappetta, "The epithelial-tomesenchymal transition in breast cancer: focus on basal-like carcinomas," Cancers, vol. 9, no. 12, p. 134, 2017. 
[111] A. Dongre and R. A. Weinberg, "New insights into the mechanisms of epithelial-mesenchymal transition and implications for cancer," Nature Reviews Molecular Cell Biology, vol. 20, no. 2, pp. 69-84, 2019.

[112] A. Alsuliman, D. Colak, O. Al-Harazi et al., "Bidirectional crosstalk between PD-L1 expression and epithelial to mesenchymal transition: significance in claudin-low breast cancer cells," Molecular Cancer, vol. 14, no. 1, p. 149, 2015.

[113] C. A. Crane, A. Panner, J. C. Murray et al., "PI(3) kinase is associated with a mechanism of immunoresistance in breast and prostate cancer," Oncogene, vol. 28, no. 2, pp. 306-312, 2009.

[114] S. Almozyan, D. Colak, F. Mansour et al., "PD-L1 promotes OCT4 and Nanog expression in breast cancer stem cells by sustaining PI3K/AKT pathway activation," International Journal of Cancer, vol. 141, no. 7, pp. 1402-1412, 2017.

[115] K. M. O'Brien, S. R. Cole, C.-K. Tse et al., "Intrinsic breast tumor subtypes, race, and long-term survival in the Carolina Breast Cancer Study," Clinical Cancer Research, vol. 16, no. 24, pp. 6100-6110, 2010.

[116] T. Pawson and G. D. Gish, "SH2 and SH3 domains: from structure to function," Cell, vol. 71, no. 3, pp. 359-362, 1992.

[117] A. Z. Elmansuri, M. A. Tanino, R. Mahabir et al., "Novel signaling collaboration between TGF- $\beta$ and adaptor protein Crk facilitates EMT in human lung cancer," Oncotarget, vol. 7, no. 19, pp. 27094-27107, 2016.

[118] M. Z. Noman, B. Janji, A. Abdou et al., "The immune checkpoint ligand $\mathrm{PD}-\mathrm{L} 1$ is upregulated in EMT-activated human breast cancer cells by a mechanism involving ZEB- 1 and miR-200," Oncoimmunology, vol. 6, no. 1, article e1263412, 2016.

[119] S. Kumar, V. Davra, A. E. Obr et al., "Crk adaptor protein promotes PD-L1 expression, EMT and immune evasion in a murine model of triple-negative breast cancer," Oncoimmunology, vol. 7, no. 1, article e1376155, 2017.

[120] C. Wei, Y. Wang, and X. Li, "The role of Hippo signal pathway in breast cancer metastasis," Oncotargets and Therapy, vol. 11, pp. 2185-2193, 2018.

[121] H. J. Janse van Rensburg, T. Azad, M. Ling et al., "The Hippo pathway component TAZ promotes immune evasion in human cancer through PD-L1," Cancer Research, vol. 78, no. 6, pp. 1457-1470, 2018.

[122] J. Díaz-Martín, M. Á. López-García, L. Romero-Pérez et al., "Nuclear TAZ expression associates with the triple-negative phenotype in breast cancer," Endocrine-Related Cancer, vol. 22, no. 3, pp. 443-454, 2015.

[123] J. Zhang, X. J. Tian, and J. Xing, "Signal transduction pathways of EMT induced by TGF-beta, SHH, and WNT and their crosstalks," Journal of Clinical Medicine, vol. 5, no. 4, 2016.

[124] L. Castagnoli, V. Cancila, S. L. Cordoba-Romero et al., "WNT signaling modulates PD-L1 expression in the stem cell compartment of triple-negative breast cancer," Oncogene, vol. 38, no. 21, pp. 4047-4060, 2019.

[125] K. Wu, H. Xu, Y. Tian et al., "The role of CD44 in epithelialmesenchymal transition and cancer development," Oncotargets and Therapy, vol. 8, pp. 3783-3792, 2015.

[126] P. Bhat-Nakshatri, H. Appaiah, C. Ballas et al., "SLUG/SNAI2 and tumor necrosis factor generate breast cells with CD44 +/CD24- phenotype," BMC Cancer, vol. 10, p. 411, 2010.
[127] J. Y. So, A. K. Smolarek, D. M. Salerno et al., "Targeting CD44-STAT3 signaling by Gemini vitamin D analog leads to inhibition of invasion in basal-like breast cancer," PLoS One, vol. 8, no. 1, article e54020, 2013.

[128] S. Liu and C. Cheng, "Akt signaling is sustained by a CD44 splice isoform-mediated positive feedback loop," Cancer Research, vol. 77, no. 14, pp. 3791-3801, 2017.

[129] G.-B. Jang, J.-Y. Kim, S.-D. Cho et al., "Blockade of Wnt/betacatenin signaling suppresses breast cancer metastasis by inhibiting CSC-like phenotype," Scientific Reports, vol. 5, p. 12465, 2015.

[130] S. Ricardo, A. F. Vieira, R. Gerhard et al., "Breast cancer stem cell markers CD44, CD24 and ALDH1: expression distribution within intrinsic molecular subtype," Journal of Clinical Pathology, vol. 64, no. 11, pp. 937-946, 2011.

[131] K. Wu, H. Xu, X. Yuan et al., "Enrichment of CD44 in basaltype breast cancer correlates with EMT, cancer stem cell gene profile, and prognosis," Oncotargets and Therapy, vol. 9, pp. 431-444, 2016.

[132] T. Kong, R. Ahn, K. Yang et al., “CD44 promotes PD-L1 expression and its tumor-intrinsic function in breast and lung cancers," Cancer Research, vol. 80, no. 3, pp. 444-457, 2020.

[133] S. S. Chung, N. Giehl, Y. Wu, and J. V. Vadgama, "STAT3 activation in HER2-overexpressing breast cancer promotes epithelial-mesenchymal transition and cancer stem cell traits," International Journal of Oncology, vol. 44, no. 2, pp. 403-411, 2014.

[134] J. Huynh, A. Chand, D. Gough, and M. Ernst, "Therapeutically exploiting STAT3 activity in cancer - using tissue repair as a road map," Nature Reviews. Cancer, vol. 19, no. 2, pp. 8296, 2019.

[135] I. Zerdes, M. Wallerius, E. G. Sifakis et al., "STAT3 activity promotes programmed-death ligand 1 expression and suppresses immune responses in breast cancer," Cancers (Basel), vol. 11, no. 10, 2019.

[136] M. P. Mak, P. Tong, L. Diao et al., "A patient-derived, pancancer EMT signature identifies global molecular alterations and immune target enrichment following epithelial-tomesenchymal transition," Clinical Cancer Research, vol. 22, no. 3, pp. 609-620, 2016.

[137] C. Moyret-Lalle, E. Ruiz, and A. Puisieux, "Epithelial-mesenchymal transition transcription factors and miRNAs: "plastic surgeons" of breast cancer," World Journal of Clinical Oncology, vol. 5, no. 3, pp. 311-322, 2014.

[138] M. Z. Noman, G. Desantis, B. Janji et al., "PD-L1 is a novel direct target of HIF-1alpha, and its blockade under hypoxia enhanced MDSC-mediated T cell activation," The Journal of Experimental Medicine, vol. 211, no. 5, pp. 781-790, 2014.

[139] I. B. Barsoum, C. A. Smallwood, D. R. Siemens, and C. H. Graham, "A mechanism of hypoxia-mediated escape from adaptive immunity in cancer cells," Cancer Research, vol. 74, no. 3, pp. 665-674, 2014.

[140] C. Hwangbo, N. Tae, S. Lee et al., "Syntenin regulates TGFbetal-induced Smad activation and the epithelial-tomesenchymal transition by inhibiting caveolin-mediated TGF-beta type I receptor internalization," Oncogene, vol. 35, no. 3, pp. 389-401, 2016.

[141] J. Liu, Y. Yang, H. Wang et al., "Syntenin1/MDA-9 (SDCBP) induces immune evasion in triple-negative breast cancer by upregulating PD-L1," Breast Cancer Research and Treatment, vol. 171, no. 2, pp. 345-357, 2018. 
[142] A. K. Pradhan, S. Maji, S. K. Das, L. Emdad, D. Sarkar, and P. B. Fisher, "MDA-9/Syntenin/SDCBP: new insights into a unique multifunctional scaffold protein," Cancer and Metastasis Reviews, vol. 39, no. 3, pp. 769-781, 2020.

[143] F. Marcucci, G. Stassi, and R. De Maria, "Epithelial-mesenchymal transition: a new target in anticancer drug discovery," Nature Reviews. Drug Discovery, vol. 15, no. 5, pp. 311-325, 2016.

[144] S. H. Choi, J. S. Chang, J. S. Koo et al., "Differential prognostic impact of strong PD-L1 expression and 18F-FDG uptake in triple-negative breast cancer," American Journal of Clinical Oncology, vol. 41, no. 11, pp. 1049-1057, 2018.

[145] N. J. Palaskas, J. D. Garcia, R. Shirazi et al., "Global alteration of T-lymphocyte metabolism by PD-L1 checkpoint involves a block of de novo nucleoside phosphate synthesis," Cell Discovery, vol. 5, p. 62, 2019.

[146] M. Irving, R. V. de Silly, K. Scholten, N. Dilek, and G. Coukos, "Engineering chimeric antigen receptor T-cells for racing in solid tumors: don't forget the fuel," Frontiers in Immunology, vol. 8, p. 267, 2017.

[147] Y. Wang, H. Wang, H. Yao, C. Li, J.-Y. Fang, and J. Xu, "Regulation of PD-L1: emerging routes for targeting tumor immune evasion," Frontiers in Pharmacology, vol. 9, p. 536, 2018.

[148] C. W. Li, S. O. Lim, W. Xia et al., "Glycosylation and stabilization of programmed death ligand-1 suppresses T-cell activity," Nature Communications, vol. 7, p. 12632, 2016.

[149] C. W. Li, S. O. Lim, E. M. Chung et al., "Eradication of triplenegative breast cancer cells by targeting glycosylated PD-L1," Cancer Cell, vol. 33, no. 2, pp. 187-201, 2018.

[150] J. Kim, J. Kong, H. Chang, H. Kim, and A. Kim, "EGF induces epithelial-mesenchymal transition through phosphoSmad2/3-Snail signaling pathway in breast cancer cells," Oncotarget, vol. 7, no. 51, pp. 85021-85032, 2016.

[151] J.-M. Hsu, W. Xia, Y.-H. Hsu et al., "STT3-dependent PD-L1 accumulation on cancer stem cells promotes immune evasion," Nature Communications, vol. 9, no. 1, p. 1908, 2018.

[152] S. Basu, S. Cheriyamundath, and A. Ben-Zeev, "Cell-cell adhesion: linking Wnt/beta-catenin signaling with partial EMT and stemness traits in tumorigenesis," F1000Research, vol. 7, article 1488, 2018.

[153] S. Eikawa, M. Nishida, S. Mizukami, C. Yamazaki, E. Nakayama, and H. Udono, "Immune-mediated antitumor effect by type 2 diabetes drug, metformin," Proceedings of the National Academy of Sciences of the United States of America, vol. 112, no. 6, pp. 1809-1814, 2015.

[154] Y. Lei, Y. Yi, Y. Liu et al., "Metformin targets multiple signaling pathways in cancer," Chinese Journal of Cancer, vol. 36, no. 1, p. 17, 2017.

[155] S. Verdura, E. Cuyàs, B. Martin-Castillo, and J. A. Menendez, "Metformin as an archetype immuno-metabolic adjuvant for cancer immunotherapy," Oncoimmunology, vol. 8, no. 10, article e1633235, 2019.

[156] Y. Ho, Y.-F. Chen, L.-H. Wang et al., "Inhibitory effect of Anoectochilus formosanus extract on hyperglycemia-related PD-L1 expression and cancer proliferation," Frontiers in Pharmacology, vol. 9, p. 807, 2018.

[157] J.-H. Cha, W.-H. Yang, W. Xia et al., "Metformin promotes antitumor immunity via endoplasmic-reticulum-associated degradation of PD-L1," Molecular Cell, vol. 71, no. 4, pp. 606-620, 2018.
[158] B. Hyun, S. Shin, A. Lee et al., "Metformin down-regulates TNF-alpha secretion via suppression of scavenger receptors in macrophages," Immune Network, vol. 13, no. 4, pp. 123132, 2013.

[159] F. V. Pereira, A. C. L. Melo, J. S. Low et al., "Metformin exerts antitumor activity via induction of multiple death pathways in tumor cells and activation of a protective immune response," Oncotarget, vol. 9, no. 40, pp. 25808-25825, 2018.

[160] V. K. Gadi and N. E. Davidson, "Practical approach to triplenegative breast cancer," Journal of Oncology Practicel American Society of Clinical Oncology, vol. 13, no. 5, pp. 293-300, 2017.

[161] D. P. Hill, A. Harper, J. Malcolm et al., "Cisplatin-resistant triple-negative breast cancer subtypes: multiple mechanisms of resistance," BMC Cancer, vol. 19, no. 1, p. 1039, 2019.

[162] M. Wangpaichitr, H. Kandemir, Y. Y. Li et al., "Relationship of metabolic alterations and PD-L1 expression in cisplatin resistant lung cancer," Cell \& Developmental Biology, vol. 6, no. 2, 2017.

[163] R. Marullo, E. Werner, N. Degtyareva et al., "Cisplatin induces a mitochondrial-ROS response that contributes to cytotoxicity depending on mitochondrial redox status and bioenergetic functions," PLoS One, vol. 8, no. 11, article e81162, 2013.

[164] M. Wangpaichitr, E. J. Sullivan, G. Theodoropoulos et al., "The relationship of thioredoxin-1 and cisplatin resistance: its impact on ROS and oxidative metabolism in lung cancer cells," Molecular Cancer Therapeutics, vol. 11, no. 3, pp. 604-615, 2012.

[165] M. A. Cichon and D. C. Radisky, "ROS-induced epithelialmesenchymal transition in mammary epithelial cells is mediated by NF- $\kappa$ B-dependent activation of snail," Oncotarget, vol. 5, no. 9, pp. 2827-2838, 2014.

[166] M. Al-Dughaishi, A. Shalaby, K. Al-Ribkhi, A. Boudaka, M.R. Boulassel, and J. Saleh, "The value of programmed death ligand 1 expression in cancer patients treated with neoadjuvant chemotherapy," Sultan Qaboos University Medical Journal, vol. 19, no. 4, pp. e277-e283, 2019.

[167] V. Pelekanou, W. E. Barlow, M.-K. von Wahlde et al., "Effects of neoadjuvant chemotherapy (NAC) on tumor infiltrating lymphocytes (TIL) and PD-L1 expression in the SWOG S0800 clinical trial," Journal of Clinical Oncology, vol. 35, Supplement 15, pp. 519-519, 2017.

[168] J. Lee, D. M. Kim, and A. Lee, "Prognostic role and clinical association of tumor-infiltrating lymphocyte, programmed death ligand-1 expression with neutrophil-lymphocyte ratio in locally advanced triple-negative breast cancer," Cancer Research and Treatment, vol. 51, no. 2, pp. 649-663, 2019.

[169] M. Pistelli, M. De Lisa, Z. Ballatore et al., "Pre-treatment neutrophil to lymphocyte ratio may be a useful tool in predicting survival in early triple negative breast cancer patients," $B M C$ Cancer, vol. 15, p. 195, 2015.

[170] D. Samanta, Y. Park, X. Ni et al., "Chemotherapy induces enrichment of CD47(+)/CD73(+)/PDL1(+) immune evasive triple-negative breast cancer cells," Proceedings of the National Academy of Sciences of the United States of America, vol. 115, no. 6, pp. E1239-E1248, 2018.

[171] R. Padmanabhan, H. S. Kheraldine, N. Meskin, S. Vranic, and A.-E. Al Moustafa, "Crosstalk between HER2 and PD-1/PDL1 in breast cancer: from clinical applications to mathematical models," Cancers, vol. 12, no. 3, 2020. 